\title{
Inverse modeling of cloud-aerosol interactions - Part 1: Detailed response surface analysis
}

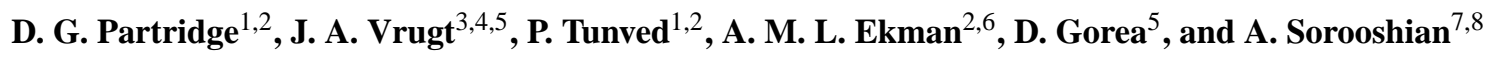 \\ ${ }^{1}$ Department of Applied Environmental Science, Stockholm University, Sweden \\ ${ }^{2}$ Bert Bolin Centre for Climate Research, Stockholm University, 10691 Stockholm, Sweden \\ ${ }^{3}$ The Henry Samueli School of Engineering, Department of Civil and Environmental Engineering, University of California, \\ Irvine, USA \\ ${ }^{4}$ Earth and Environmental Sciences Division, Los Alamos National Laboratory, Mail Stop T003, Los Alamos, \\ NM, 87545, USA \\ ${ }^{5}$ Computational Geo-Ecology, Institute for Biodiversity and Ecosystem Dynamics, University of Amsterdam, Amsterdam, \\ The Netherlands \\ ${ }^{6}$ Department of Meteorology, Stockholm University, Sweden \\ ${ }^{7}$ Department of Chemical and Environmental Engineering, The University of Arizona, Tucson, USA \\ ${ }^{8}$ Department of Atmospheric Sciences, The University of Arizona, Tucson, USA
}

Received: 21 December 2010 - Published in Atmos. Chem. Phys. Discuss.: 9 February 2011

Revised: 17 June 2011 - Accepted: 7 July 2011 - Published: 25 July 2011

\begin{abstract}
New methodologies are required to probe the sensitivity of parameters describing cloud droplet activation. This paper presents an inverse modeling-based method for exploring cloud-aerosol interactions via response surfaces. The objective function, containing the difference between the measured and model predicted cloud droplet size distribution is studied in a two-dimensional framework, and presented for pseudo-adiabatic cloud parcel model parameters that are pair-wise selected. From this response surface analysis it is shown that the susceptibility of cloud droplet size distribution to variations in different aerosol physiochemical parameters is highly dependent on the aerosol environment and meteorological conditions. In general the cloud droplet size distribution is most susceptible to changes in the updraft velocity. A shift towards an increase in the importance of chemistry for the cloud nucleating ability of particles is shown to exist somewhere between marine average and rural continental aerosol regimes.

We also use these response surfaces to explore the feasibility of inverse modeling to determine cloud-aerosol interactions. It is shown that the "cloud-aerosol" inverse problem is
\end{abstract}

particularly difficult to solve due to significant parameter interaction, presence of multiple regions of attraction, numerous local optima, and considerable parameter insensitivity.

The identifiability of the model parameters will be dependent on the choice of the objective function. Sensitivity analysis is performed to investigate the location of the information content within the calibration data to confirm that our choice of objective function maximizes information retrieval from the cloud droplet size distribution.

Cloud parcel models that employ a moving-centre based calculation of the cloud droplet size distribution pose additional difficulties when applying automatic search algorithms for studying cloud-aerosol interactions. To aid future studies, an increased resolution of the region of the size spectrum associated with droplet activation within cloud parcel models, or further development of fixed-sectional cloud models would be beneficial. Despite these improvements, it is demonstrated that powerful search algorithms remain necessary to efficiently explore the parameter space and successfully solve the cloud-aerosol inverse problem. 


\section{Introduction}

A challenge currently facing the cloud-aerosol research community is quantifying the relative importance of aerosol size and composition for the activation of particles into cloud droplets (McFiggans et al., 2006). The difficulties in accurately representing the development of a cloud droplet number concentration (CDNC) distribution using numerical approaches can be partly attributed to the current state of knowledge regarding which of the parameters describing the properties of an aerosol distribution are most important for the cloud nucleating ability of aerosol particles (Dusek et al., 2006). This capability is a function of the size of the particle, its composition and mixing state, and the supersaturation in the cloud (Fitzgerald, 1974; Hegg and Larson, 1990; Laaksonen et al., 1998; Feingold, 2003; Conant et al., 2004; Kanakidou et al., 2005; Andreae and Rosenfeld, 2008; Quinn et al., 2008).

The aerosol indirect effect (Lohmann and Feichter, 2005) remains the largest single source of uncertainty in current estimates of the total anthropogenic radiative forcing in climate models (IPCC, 2007). The indirect effect can be described as the change in the microphysical and macrophysical properties of clouds in response to a change in input aerosol properties. To constrain the uncertainty of the indirect effect it is necessary to better understand cloud-aerosol interactions; hence it is crucial to improve the understanding of both the physiochemical properties of the aerosol, and the meteorological parameters relevant for the formation and development of clouds. One approach to address this question is to use model sensitivity studies (e.g. Nenes et al., 2001; Feingold, 2003; Rissman et al., 2004; Anttila and Kerminen, 2007; Reutter et al., 2009). However, most sensitivity studies to date have been local, i.e. investigating parameter sensitivity in the vicinity of their actual values. Global sensitivity analysis considers parameter changes over the entire multi-dimensional parameter domain (e.g. Pérez et al., 2006; Anttila and Kerminen, 2007). This generally leads to different, but more reliable results because parameter sensitivities in nonlinear models typically vary considerably over the feasible space of solutions.

One route by which cloud-aerosol relationships can be probed in detail is to embrace inverse modeling techniques, to scrutinize and evaluate model parameter interactions over a wide range of input and output conditions. In inverse analysis, a given model is calibrated by iteratively changing input values (calibration parameters herein) until the simulated output values match the measured data (termed calibration data herein) as closely and consistently as possible.

Inverse modeling has many practical advantages, but a key advantage is that, when properly implemented, it allows the conditioning of parameter sensitivity and correlation on real world measurements. Parameter estimation by inverse modeling also provides a useful approach to diagnose structural inaccuracies in a model, which will appear as a mismatch between optimised parameter values and their directly-observed values. In essence, improved interpretation of parameter uncertainty can yield valuable information to enable a better judgement of the limits of our theoretical understanding of droplet activation. When applying an inverse approach to a new problem or model, it is prudent to first investigate the posedness and identifiability of the model parameters (Pollacco and Angulo-Jaramilo, 2009; Cressie et al., 2009). One method to achieve this is via response surface analysis (Toorman et al., 1992; Šimůnek et al., 1998; Vrugt et al., 2001).

In addition to exploring the posedness of an inverse problem, response surfaces can also be used to provide a qualitative graphical illustration of the outcome of global sensitivity analysis. For example, the susceptibility of cloud albedo and precipitation to aerosol perturbations (Platnick and Twomey, 1994; Noone et al., 2000; Sorooshian et al., 2009) could be investigated by using response surfaces to provide detailed insight to the structural response of certain calibration data to any calibration parameters of interest in two dimensions.

\subsection{An introduction to inverse modeling}

Parameter estimation or model calibration is a common problem in many areas of process modeling, both in on-line applications, such as real time optimization, and in off-line applications, such as the modeling of reaction kinetics and phase equilibrium. The goal is to determine values of model parameters that provide the best fit to measured data, generally based on some type of least squares or maximum likelihood criterion (Vrugt et al., 2006). Usually, this requires the solution of a nonlinear and frequently non-convex optimization problem.

During the last two decades a great deal of research has been devoted to the application of inverse modeling for model calibration in many different areas of scientific research (Vrugt et al., 2004, 2008; Voutilainen and Kaipo, 2005; San Martini et al., 2006; Tomassini et al., 2007; Laine and Tamminen, 2008; Wraith et al., 2009; Bikowski et al., 2010; Järvinen et al., 2010; Loridan et al., 2010). Crump and Seinfeld (1982) and Twomey (1975) were among the first to apply inverse modeling for calibration of aerosol size distribution properties from instruments (Kandlikar and Ramachandran, 1999). Inverse modeling is particularly useful for finding model parameters whose values cannot be measured directly at the (application) scale of interest.

To illustrate the inverse modeling approach consider Fig. 1, which presents a schematic representation of the model calibration problem. Using a priori values of the calibration parameters, the predictions of the calibration data by the model (indicated with solid-red line) are behaviourally consistent with the observations (dotted line), but demonstrate a significant bias in the smaller part of the size distribution. The common approach is to ascribe this mismatch between model and observations to parameter uncertainty. 

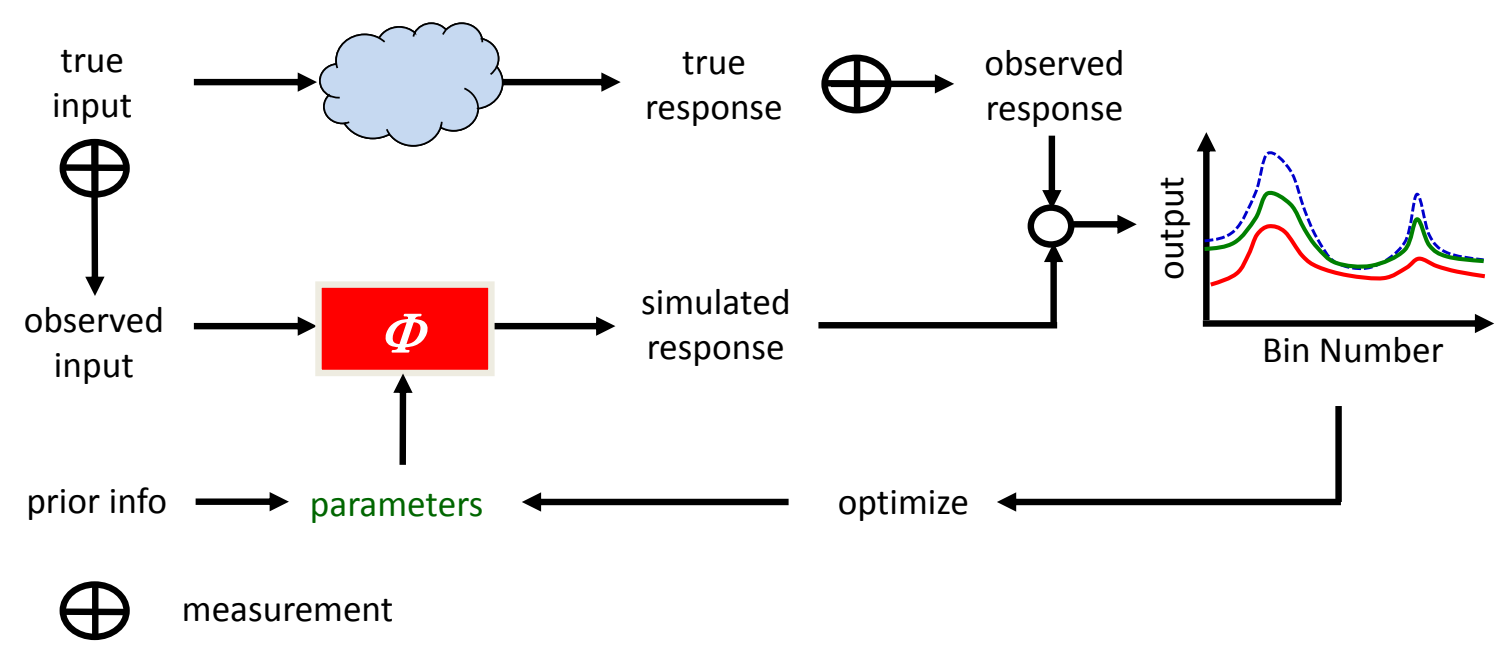

Fig. 1. A schematic representation of inverse modeling. The rectangular box in the bottom panel $\Phi$ represents the cloud parcel model that is being used to predict the observed particle size distribution from given input data (also called forcing or boundary conditions), and some a-priori values of the model parameters. The model parameters are iteratively adjusted so that the predictions of the model, $\Phi$ (represented by the green and red solid lines) approximate as closely and consistently as possible the observed response (measured particle size distribution).

Mathematically, the model calibration problem depicted in Fig. 1 can be formulated as follows. Let $\tilde{\boldsymbol{Y}}=\Phi(X, \theta)$ denote predictions of, for instance the cloud droplet size distribution, $\tilde{\boldsymbol{Y}}=\left\{\tilde{y}_{1}, \ldots, \tilde{y}_{n}\right\}$ of the cloud parcel model $\Phi$ with observed input variables $X$ and model parameters $\theta$. Let $\boldsymbol{Y}=\left\{y_{1}, \ldots, y_{n}\right\}$ represent the observed cloud droplet size distribution (where $n$ corresponds to the resolution). After running the cloud parcel model with a set of parameters and input variables we are left with a predicted size distribution $\tilde{\boldsymbol{Y}}$ that we need to compare against the observations, $\boldsymbol{Y}$. The difference between the model-predicted and measured cloud droplet size distribution can be represented by the residual vector $\boldsymbol{E}$ as:

$$
\begin{aligned}
\boldsymbol{E}(\theta) & =G(\tilde{\boldsymbol{Y}})-G(\boldsymbol{Y})=\left\{G\left(\tilde{y}_{1}\right)-G\left(y_{1}\right), \ldots, G\left(\tilde{y}_{n}\right)-G\left(y_{n}\right)\right\} \\
& =\left\{e_{1}(\theta), \ldots, e_{n}(\theta)\right\}
\end{aligned}
$$

where $G($.) allows for various monotonic (such as logarithmic) transformations of the model outputs. In practice however, it is particularly difficult to work with an $n$-element vector of residuals, $\boldsymbol{E}(\theta)$, and find the best parameter values. It has therefore become common practice to aggregate the vector of residuals (Eq. 1), $\boldsymbol{E}\left(\theta=\left\{e_{1}(\theta), \ldots, e_{n}(\theta)\right\}\right.$ into a single measure of distance between the model predictions and observations. This measure is commonly called the objective function (herein denoted as "OF").

The inverse modeling approach now relies on the estimation of the set of parameters $\theta$ such that the OF is in some sense forced to be as close to zero as possible. To minimize the OF, the calibration parameters needed to perform the numerical simulation are optimised using an inverse analysis algorithm. If the model fit is not "optimal" the procedure is repeated until the model is optimized.

\subsection{Goals}

The ultimate goal is to apply an automatic parameter estimation algorithm to a pseudo-adiabatic cloud parcel model. This will be described in detail in the second paper in this series (Partridge et al., 2011). However, the first critical step described here, is to study the behaviour of the chosen form of the $\mathrm{OF}$ in the multi-dimensional parameter space of the model used (cf. Sect. 3.1). This will be achieved by studying response surfaces, a form of analysis which has previously been used in many fields (Sorooshian and Arfi, 1982; Toorman et al., 1992; Šimůnek et al., 1998; Vrugt et al., 2001). These response surfaces will also be used to provide 2-D sensitivity information to complement Partridge et al. (2011) in which the sensitivity resulting from changing more than two parameters simultaneously is presented.

The main goals of this paper are split into two distinctive applications:

1. Explore the feasibility of inverse modeling for the calibration of a pseudo-adiabatic cloud parcel model using artificial measurements generated from this model (Sects. 3.1-3.3).

2. Investigate cloud-aerosol interactions with respect to the susceptibility of the cloud droplet size distribution to aerosol physiochemical and meteorological parameters (Sect. 3.4).

To achieve these goals, response surfaces will be generated for a range of aerosol environments (marine arctic, marine average, rural continental and polluted continental). The response surfaces are calculated by solving the OF for many possible combinations of selected pairs of parameters from 
Table 1. Model parameter values used to generate synthetic data for marine Arctic and marine average aerosol environments (bold), as well as lower and upper parameter bounds used to generate the grid over which the response surfaces were calculated.

\begin{tabular}{ll|rrr|rrr}
\hline & Environment & \multicolumn{3}{|c|}{ Marine Arctic } & \multicolumn{3}{c}{ Marine Average } \\
\hline & Parameter & Lower Limit & True Value & Upper Limit & Lower Limit & True Value & Upper Limit \\
\hline 1 & Mass Accom Coefficient & 0.01 & $\mathbf{1 . 0 0}$ & 1.00 & 0.01 & $\mathbf{1 . 0 0}$ & 1.00 \\
2 & Surface Tension $\left(\mathrm{m} \mathrm{N}^{-1}\right)$ & 20.00 & $\mathbf{7 0 . 0 0}$ & 75.00 & 20.00 & $\mathbf{7 0 . 0 0}$ & 75.00 \\
3 & ${\text { Updraft }\left(\mathrm{m} \mathrm{s}^{-1}\right)}^{\text {N1 }\left(\mathrm{cm}^{-3}\right)}$ & 0.05 & $\mathbf{0 . 3 0}$ & 2.00 & 0.05 & $\mathbf{0 . 3 0}$ & 2.00 \\
4 & 33.00 & $\mathbf{8 0 . 0 0}$ & 185.00 & 150.00 & $\mathbf{2 6 5 . 0 0}$ & 600.00 \\
5 & R1 $(\mathrm{nm})$ & 13.50 & $\mathbf{1 7 . 4 0}$ & 21.50 & 15.50 & $\mathbf{2 1 . 0 0}$ & 23.50 \\
6 & GSD1 & 1.30 & $\mathbf{1 . 4 3}$ & 1.60 & 1.40 & $\mathbf{1 . 4 5}$ & 1.60 \\
7 & N2 $\left(\mathrm{cm}^{-3}\right.$ ) & 36.50 & $\mathbf{7 4 . 5 0}$ & 150.00 & 60.00 & $\mathbf{1 6 5 . 0 0}$ & 250.00 \\
8 & R2 $(\mathrm{nm})$ & 35.00 & $\mathbf{4 8 . 0 0}$ & 65.00 & 70.00 & $\mathbf{8 2 . 5 0}$ & 100.00 \\
9 & GSD2 & 1.50 & $\mathbf{1 . 6 8}$ & 1.85 & 1.40 & $\mathbf{1 . 5 0}$ & 1.60 \\
10 & Soluble Mass Fraction & 0.05 & $\mathbf{0 . 6 0}$ & 1.00 & 0.05 & $\mathbf{0 . 9 0}$ & 1.00 \\
\hline
\end{tabular}

Tables 1 and 2 on a rectangular grid. A response surface is then obtained by changing these two selected parameters around their true values, whilst keeping other parameters constant at their true values.

The paper is organized as follows: firstly the pseudoadiabatic cloud parcel model and the method used to generate synthetic measurements will be described. The use of response surface analysis to aid the selection of an appropriate $\mathrm{OF}$ will then be discussed in terms of the identifiability of model calibration parameters and information content of the calibration data. Implications of the standard output of particle size distributions from cloud parcel models will then be highlighted. Secondly, by representing the deviation from base case droplet size distributions by the OF, the applicability of response surface analysis to determine droplet size distribution susceptibility regimes for different (aerosol) environments will be presented.

Finally an example of the need for robust search algorithms will be presented by overlaying the results of a simulation from a deterministic optimisation algorithm versus a standard Latin Hypercube Monte Carlo simulation onto response surfaces.

\section{Materials and methods}

\subsection{Pseudo-adiabatic cloud parcel model}

In the present study, we use a pseudo-adiabatic cloud parcel model to generate the synthetic calibration data sets and the inversion analysis performed in this study. Such a model offers the possibility of studying the relationship between key input parameters with respect to different output variables in a computationally efficient way. Adiabatic cloud parcel models have been evaluated against in-situ observations to estimate the impact of aerosol size/composition for liquid clouds (Ayers and Larson, 1990; Nenes et al., 2002; Hsieh et al., 2009). We posit that a pseudo-adiabatic cloud parcel model is a sensible trade-off between processes accounted for, and computational speed necessary to perform the thousands of simulations required for the Markov Chain Monte Carlo simulation (MCMC) of a single cloud case.

For more information on the pseudo-adiabatic cloud model and references the reader is referred to Roelofs and Jongen (2004). The model simulates the pseudo-adiabatic ascent of an air parcel, condensation and evaporation of water vapor on aerosols, particle activation, condensational growth, collision and coalescence between droplets, and aqueous phase sulfur chemistry. It can be initialized with aerosol populations consisting of one or more internal and/or external mixtures of $\left(\mathrm{NH}_{4}\right)_{m} \mathrm{H}_{2-m} \mathrm{SO}_{4}(m=0,1$ or 2$)$, organic carbon (OC), black carbon (BC), mineral dust and sea salt. The model is currently configured so that the aerosol is represented as an internal mixture of compounds. This should be a reasonable assumption for aged aerosol in the marine environment but may be less realistic for rural/polluted continental conditions. Nevertheless we keep the mixing state consistent to allow a more straight-forward analysis. The size distribution of the aerosol size distribution is described by two lognormal modes, which are defined by the geometric standard deviation of the mode, total particle concentration, and mean radius. These lognormal parameters are used to generate an aerosol number size distribution over 300 size bins covering a size range of $4-2000 \mathrm{~nm}$. Each aerosol bin is characterized by a dry and a wet particle radius, the latter of which employs a moving centre approach so that the wet radii are continuously modified by condensation or evaporation of water.

The ascending parcel equations are from Pruppacher and Klett (1997). Aerosol activation and condensation/ evaporation of water are calculated according to the Köhler equation (Köhler, 1936) and parameterized according to Hänel (1987). The Köhler equation was reformulated in 
Table 2. Model parameter values used to generate synthetic data for rural continental and polluted continental aerosol environments (bold), as well as lower and upper parameter bounds used to generate the grid over which the response surfaces were calculated.

\begin{tabular}{|c|c|c|c|c|c|c|c|}
\hline & \multirow{2}{*}{$\begin{array}{l}\text { Environment } \\
\text { Parameter }\end{array}$} & \multicolumn{3}{|c|}{ Rural Continental } & \multicolumn{3}{|c|}{ Polluted Continental } \\
\hline & & Lower Limit & True Value & Upper Limit & Lower Limit & True Value & Upper Limit \\
\hline 1 & Mass Accom Coefficient & 0.01 & 1.00 & 1.00 & 0.01 & 1.00 & 1.00 \\
\hline 2 & Surface Tension $\left(\mathrm{m} \mathrm{N} \mathrm{m}^{-1}\right)$ & 20.00 & 70.00 & 75.00 & 20.00 & 70.00 & 75.00 \\
\hline 3 & $\operatorname{Updraft}\left(\mathrm{m} \mathrm{s}^{-1}\right)$ & 0.05 & 0.30 & 2.00 & 0.05 & 0.30 & 2.00 \\
\hline 4 & $\mathrm{~N} 1\left(\mathrm{~cm}^{-3}\right)$ & 450.00 & 1010.00 & 1600.00 & 2900.00 & 4900.00 & 9100.00 \\
\hline 5 & $\mathrm{R} 1$ (nm) & 16.00 & 23.70 & 32.00 & 24.00 & 33.00 & 40.00 \\
\hline 6 & GSD1 & 1.55 & 1.71 & 1.90 & 1.47 & 1.55 & 1.66 \\
\hline 7 & $\mathrm{~N} 2\left(\mathrm{~cm}^{-3}\right)$ & 215.00 & 451.00 & 690.00 & 730.00 & 1200.00 & 1600.00 \\
\hline 8 & $\mathrm{R} 2$ (nm) & 75.00 & 89.80 & 105.00 & 75.00 & 93.50 & 105.00 \\
\hline 9 & GSD2 & 1.40 & 1.58 & 1.75 & 1.50 & 1.55 & 1.62 \\
\hline 10 & Soluble Mass Fraction & 0.05 & 0.70 & 1.00 & 0.05 & 0.60 & 1.00 \\
\hline
\end{tabular}

terms of the solute concentrations (Roelofs, 1992) to allow for modifications of the Raoult term by chemical processes, e.g., dissolution of gaseous $\mathrm{HNO}_{3}$ or partial dissolution of aerosol organic matter.

For this study the model is run with the processes of collision-coalescence and entrainment turned off, and the updraft velocity kept constant. This maintains computational speed and is deemed reasonable for this study, in which the focus is on cloud condensation nuclei (CCN) activation and condensational growth above the cloud base. In reality clouds are more complex in nature, including processes such as mixing, variable updrafts and entrainment. The approach of this study will therefore only probe an idealised system; nevertheless, it addresses the most critical cloud/droplet forming mechanisms.

\subsection{Artificial measurements}

To benchmark our inverse modeling approach, it is useful to start our analysis with numerically generated calibration data sets in the form of droplet size distributions simulated by the cloud parcel model (cf. Sect. 2.1). This "synthetic" calibration data set serves as the "truth", and was created using input parameter values from the literature. Since the exact values of the aerosol/chemistry/meteorological calibration parameters are known precisely a-priori (Toorman et al., 1992; Šimůnek et al., 1998), this enables us to analyze possible discrepancies between the estimated and true parameters and thus test our methodology. Using real-world data, parameters will diverge from their true values because of model and measurement error. It is important that first the optimal solutions of the calibration parameters can be accurately and efficiently found using synthetic calibration data with an automatic search algorithm, or else solutions found when calibrated against real world measurements could be misleading.

\subsubsection{Calibration input parameters}

To test a wide range of input aerosol size distributions and encompass the large variety of conditions observed in the aerosol/climatic system, data from four distinctively different aerosol environments were used:

1. Marine Arctic: summertime measurements performed at Ny-Ålesund, Svalbard (P. Tunved, personal communication, 2011)

2. Marine average: global measurements (Heintzenberg et al., 2000).

3. Rural continental: measurements from the wellestablished SMEAR II station at Hyytiälä (Tunved et al., 2005).

4. Polluted continental: summer continental air mass measurements from Melpitz station (Birmili et al., 2001).

The base values used to generate the calibration data are presented in Tables 1 and 2 for the parameters describing the lognormal aerosol size distribution for both the Aitken (mode 1) and accumulation (mode 2) (parameters 4-9). For each environment the upper and lower parameter bounds for these parameters were selected using the statistics from P. Tunved, personal communication, 2011; Heintzenberg et al., 2000; Tunved et al., 2005; and Birmili et al., 2001 respectively as a guide. The aerosol size distributions for each environment are shown in Fig. 2. For the updraft velocity, the base value was chosen to be $0.3 \mathrm{~m} \mathrm{~s}^{-1}$, with a lower limit of $0.05 \mathrm{~m} \mathrm{~s}^{-1}$ and upper limit of $2 \mathrm{~m} \mathrm{~s}^{-1}$, which represents a wide range of meteorological conditions. For the mass accommodation coefficient, the base value was chosen to be 1 , with a lower limit of 0.01 and upper limit of 1 . For the surface tension, the base value was chosen to be $70 \mathrm{~m} \mathrm{~N} \mathrm{~m}^{-1}$, with a lower limit of $20 \mathrm{~m} \mathrm{~N} \mathrm{~m}^{-1}$ and upper limit of $75 \mathrm{~m} \mathrm{~N} \mathrm{~m}^{-1}$. The base value 

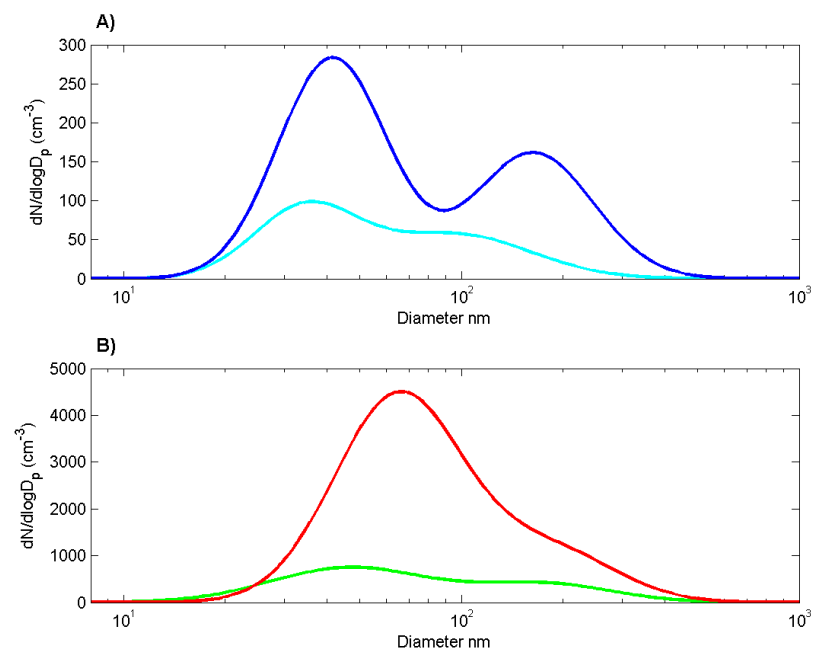

Fig. 2. (A) The initial aerosol size distributions for marine Arctic (cyan) and marine average (blue) used to calculate the respective calibration data sets. (B) The initial aerosol size distributions for rural continental (green) and polluted continental (red) used to calculate the respective calibration data sets.

and upper/lower limits for the updraft, mass accommodation coefficient and surface tension were kept fixed for all environments to allow easier comparison of the behaviour of the calibration parameters describing the aerosol's physiochemical properties.

Ideally the chemistry would be represented by the mass fractions of multiple aerosol components. This however, is not conducive for two-dimensional parameter analysis, since in order to vary parameter values independently from one another it is not possible to include mass fractions for multiple components, whilst simultaneously keeping all other components fixed and achieving unity for the sum of all mass fractions (MF). Thus, in this study the chemistry was defined as a two-component scheme consisting of either a soluble component, ammonium bisulphate $\left(\mathrm{NH}_{4} \mathrm{HSO}_{4}\right)$, or an insoluble component, black carbon (BC). In the calculation of the response surfaces (cf. Sect. 3 onwards) we only allow one of the chemistry components to vary. The soluble mass fraction (MF) is allowed to vary between 0.05 and 1 , and the MF of the insoluble component is calculated directly from the equation, $\mathrm{MF}_{\text {INSOLUBLE }}=1-\mathrm{MF}_{\text {SOLUBLE}}$. It is important that the base MFSOLUBLE used to generate our calibration data changes with different aerosol environments as for instance a marine aerosol environment would be expected to have a higher $\mathrm{MF}_{\text {SOLUBLE }}$ than a rural continental aerosol environment (Lance et al., 2004). Accordingly we use literature values as a guideline when defining the base soluble mass fraction (Zhou et al., 2001; O’Dowd et al., 2004; Neusüß et al., 2002).

In the pseudo-adiabatic cloud parcel model it is necessary to define an ambient temperature profile. In the absence of detailed prior information, we define two summer tempera- ture profiles for the four aerosol environments using standard atmospheric lapse rates generated from surface temperatures. For marine arctic conditions we assume a surface temperature of $273.15 \mathrm{~K}$. For the remaining three environments we assume a mid-latitude surface temperature of $288.15 \mathrm{~K}$.

A log-transformation was applied to the number of aerosol particles in the Aitken and Accumulation mode (calibration parameters 4, 7; see Tables 1 and 2), as the ranges of these vary by several orders of magnitude. Such transformation generally improves parameter search efficiency. Hence, these calibration parameters are sampled in the transformed space and then back-transformed before running the cloud parcel model.

\subsubsection{Synthetic calibration data}

Within an inverse modeling framework the choice of calibration data is an important factor, as this information is directly translated into the calibration parameter values. To examine aerosol-cloud interactions, in particular the influence of aerosols on the cloud microphysical properties, the change in cloud model output properties that are of most interest are the liquid water content (LWC), cloud droplet effective radius $\left(R_{\mathrm{e}}\right)$, droplet size distribution, cloud fraction, and cloud phase. In this first paper, we are focusing on liquid-phase clouds using a pseudo-adiabatic cloud parcel model; hence we are limited to investigating microphysical properties from the model output in the form of droplet number distributions or bulk parameters describing this distribution. In this investigation we define the calibration data $\boldsymbol{Y}=\left\{y_{1}, \ldots, y_{n}\right\}$ by calculating base case cloud droplet size distributions in the form $d N / d \log D_{\mathrm{p}}$ for our four aerosol environments (depicted in Fig. 3), using the base input parameter values reported in Tables 1 and 2. In all the calculations reported herein, the droplet size distribution model output is taken at $100 \mathrm{~m}$ above the cloud base. This is deemed a reasonable height within the cloud to account for droplet activation, and ensures computational tractability as each model simulation can be performed within a reasonable time frame. The following analysis will focus on the activated part of these droplet size distributions only.

\subsection{Objective Function (OF)}

The development of an appropriate OF (cf. Sect. 1.1) is typically based on assumptions regarding the distributions of the measurement errors presented in the data. Arguably, the most common OF is the simple least squares (SLS) or maximum likelihood estimator, appropriate when the measurement errors are believed to be homoscedastic and uncorrelated. We follow this assumption and use the following definition of the OF: 
$\mathrm{OF}=\sum_{i=1}^{n} w_{i}\left[y_{i}-\Phi\left(X_{i}, \theta\right)\right]^{2}=\sum_{i=1}^{n} w_{i} e_{i}(\theta)^{2}$

with the assumption of similar weights for each observation. This function is similar to the sum of squared errors (SSE) function used in many other fields of study to minimise the quadratic simulation error during model calibration. Note that the minimum value of the OF for a numerically generated data set with no error is zero. The $\boldsymbol{\theta}$ vector consists of the calibration parameters, for instance those describing the input lognormal aerosol size distribution over different modes, updraft, and mass fractions of chemical compounds, whilst the $w_{i}$ denotes the weights associated with a particular measurement point. In the absence of compelling prior information about the measurement error it is common practice to weight the observations by their respective measurement variance (Šimůnek et al., 1998). If the errors are believed to be heteroscedastic the weights should be adjusted to reflect this deviation from a single fixed measurement error variance. In this paper we are using synthetically generated observations, and the weights of the individual data points are assumed to be equal to one.

The projection of an $n$-dimensional observation space onto a single dimension $\mathrm{OF}$, results in a major loss of information from the original data (Vrugt et al., 2003; Gupta et al., 2008), thus the definition of the OF (Eq. 2) exerts a strong influence on the identifiability of the different cloud-parcel model parameters. It is important to construct an OF that contains independent (orthogonal) information about each of the individual calibration parameters. Such an OF is sensitive to each individual parameter and therefore should contain a well-defined global optimum within the parameter space. If we cannot find a single OF deemed appropriate for each of the parameters then it is worthwhile to consider multi-criteria optimization methods that simultaneously minimize different objective functions that each measure different components of model performance (Gupta et al., 1998; Vrugt et al., 2003).

When defining a suitable OF from a cloud parcel model a primary difficulty arises. Adiabatic cloud parcel models typically employ a moving centre approach for the numerical representation of the particle size distribution (Jacobson, 1997; Korhonen et al., 2005) as a moving centre based structure most accurately reproduces the qualitative features of the size distribution (Zhang et al., 1999). However, from an inverse modeling perspective a moving centre approach has distinct disadvantages. As both $x$ (radius) and $y$ (number of droplets) are simultaneously changing in each run, it is not trivial to compare measured and modelled size distributions. In order for the difference between measured and simulated $y$ values to prove an accurate diagnostic for the distance between the model predicted droplet size distribution and observational data, the model should output $y$-values at values

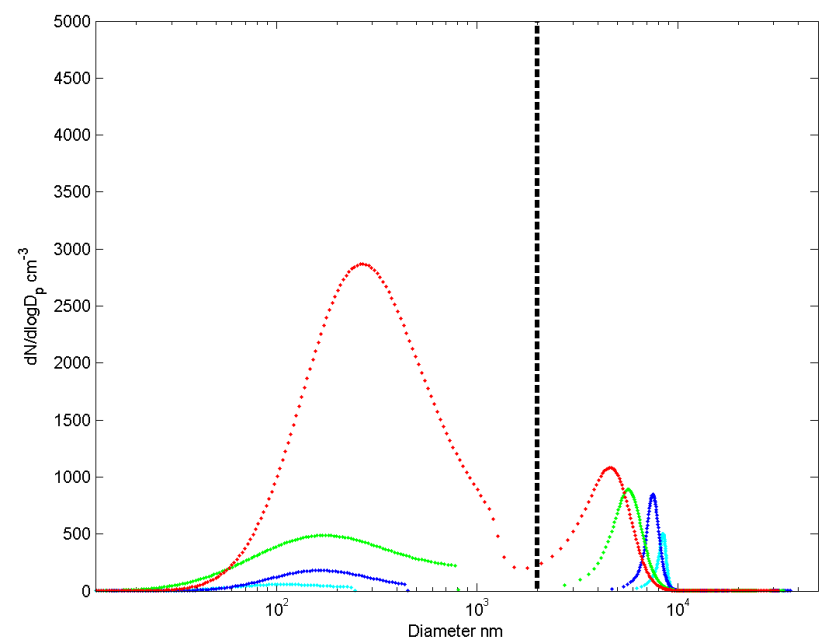

Fig. 3. The $d N / d \log D_{\mathrm{p}}$ particle size distribution generated for marine Arctic (cyan), marine average (blue), rural continental (green) and polluted continental (red) aerosol environments. Black dotted line represents location of $1 \mu \mathrm{m}$ radius.

of $x$ where we have measurements. In this study our calibration data $\boldsymbol{Y}=\left\{y_{1}, \ldots, y_{n}\right\}$ is the droplet size distribution (cf. Sect. 2.2.2), thus the corresponding model predictions of the pseudo-adiabatic model, $\tilde{\boldsymbol{Y}}=\left\{\tilde{y}_{1}, \ldots, \tilde{y}_{n}\right\}$ would need to be either re-binned or interpolated onto the size grid of $\boldsymbol{Y}=\left\{y_{1}, \ldots, y_{n}\right\}$ to ensure consistent parameter estimates that accurately represent the measured droplet-size distribution.

A standard re-binning of the size distribution onto a fixed grid has the potential to introduce problems, as the shape of the output size distribution will change significantly due to a loss of resolution. The loss of resolution will lead to a very "spiky" droplet size distribution, with the majority of the information content stored within the peak over a limited number of bins. This has the potential to create an ill-posed or "non-unique" inverse problem, the extent to which will be dependent on the original shape of the droplet size distribution. Therefore, prior to calculating the OF in this study, we apply a standard interpolation of the droplet size distribution to obtain model predictions that correspond exactly with the calibration wet particle radii.

\section{Results and discussion}

\subsection{Response surface analysis as a graphical tool: inverse problems}

Response surfaces convey important information about the posedness of an inverse problem. It is stressed that the behaviour of the OF in these parameter planes can only suggest how the OF might behave in our possible 10-dimensional continuum. For example, local minima of the OF could exist and not show up in the cross-sectional planes (Šimůnek et 
al., 1998; Vrugt et al., 2001). However, the response surfaces provide a useful approximate view of the behaviour of the $\mathrm{OF}$ in the entire parameter space. If the response surfaces do not display a well-defined global minimum in the two-dimensional parameter planes, the conventional inverse parameter estimation technique may certainly be expected to be unsuccessful in a multidimensional plane.

Response surfaces that are smooth (deterministic) and contain a single well-defined minimum are preferred, as the gradient points to the same minimum anywhere in the search space, irrespective of the location in the feasible parameter domain. Such surfaces indicate the presence of sensitive calibration parameters that could be efficiently solved using any type of search algorithm (Luo et al., 2009). An example of a response surface containing a relatively small basin of attraction is shown in Fig. 4d. For this parameter combination the OF values smoothly decrease in a generally convex manner towards the location of the optimal solution denoted by the blue cross.

Response surfaces that are flat (OF is insensitive to changes in parameter values) are more difficult to traverse as the direction of improvement is difficult to find, indicating the presence of parameter $(s)$ that are non-identifiable, which in turn can lead to non-uniqueness. Non-uniqueness indicates the presence of more than one set of calibration parameters, each yielding minimum values for the OF (Sorooshian and Gupta, 1985; Duan et al., 1992), i.e. the posterior distribution of parameter values from an optimisation would exhibit virtually identical OF values. Thereby, the information content available does not allow a single or unambiguous mathematical solution to the identification problem (Vrugt et al., 2001, 2005; Beven, 2006). Non-uniqueness not only makes it difficult to find the appropriate parameter values, but often also translates into considerable parameter uncertainty.

Examples of non-identifiable calibration parameter combinations are illustrated for marine average aerosol environments in Fig. 4b. For this cleaner environment, changes in the accumulation mode radius result in insignificant changes in the $\mathrm{OF}$, as seen in the $\mathrm{x}$-plane of the response surface. For polluted continental aerosol conditions, these same two parameters exhibit a well defined optimum. Therefore, for certain parameter combinations, the existence of nonidentifiability depends on the pre-existing aerosol and meteorological conditions. Parameters were also located that were non-identifiable for all aerosol environments. This was found to be the case for the lognormal aerosol parameters describing the Aitken mode (cf. Sect. 3.3), as well as the mass accomodation coefficient (figures not shown). The synthetic measurements simply do not contain the appropriate and required information to warrant their estimation. It is unlikely that such parameters can be estimated using current available observations.
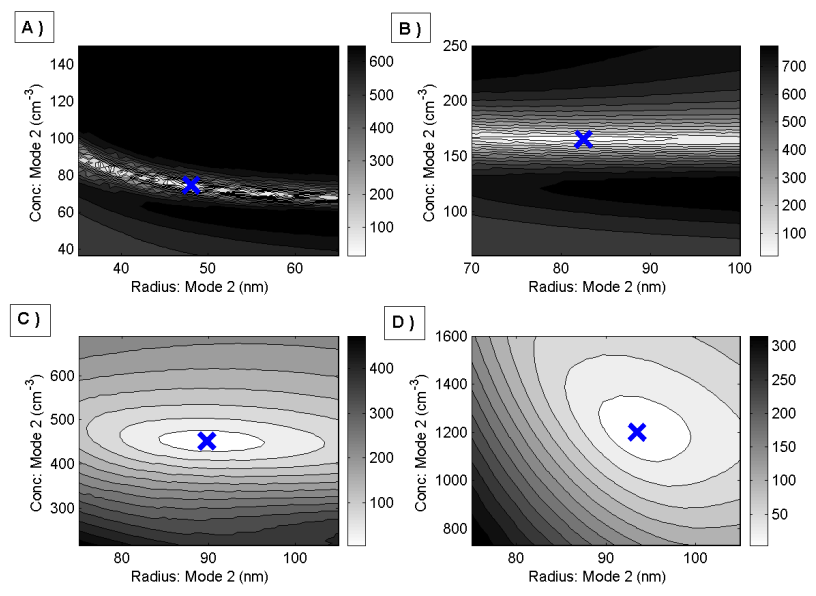

Fig. 4. (A-D) 2-D response surface planes for a selection of two parameter combinations. The blue cross denotes the true parameter values used to generate the synthetic measurements. Greyscale shows the change in gradient of the OF: (A) marine Arctic; (B) marine average; (C) rural continental; (D) polluted continental.

Response surfaces for certain calibration parameters were found to exhibit partially non-identifiable characteristics. An example of these poorly constrained parameters can be seen for rural continental aerosol conditions in Fig. 4c. The OF is relatively insensitive to changes in the accumulation mode radius up to a certain point in the parameter space.

Non-identifiable calibration parameter combinations aside, there are also other factors which can impede inverse modeling. Response surfaces that exhibit an erratic (chaotic) pattern, and/or contain multiple basins of attraction, are also particularly difficult to solve as the parameter space may contain numerous (possibly uncountable) local "minima" which may occur both close to and at various distances from the best solution (Duan et al., 1993). If several major regions of attraction exist into which an algorithm may converge (i.e. it is non-convex), and if the parameters exhibit varying degrees of sensitivity and a great deal of highly non-linear interaction it can make it difficult for an automatic search algorithm to find which of the local minima is the global minimum, and hence the true solution to the inverse problem.

A multi-modal response surface with minima both near and far from the position of the true solution was found for numerous response surfaces. This is shown for marine average conditions by the updraft versus surface tension (Fig. 5). The OF for this response surface is represented now in the $Z$ co-ordinate, so the difficulty of a search algorithm becoming trapped within a local minima can be more easily visualised. We posit that the presence of these local minima can be partially attributed to the interpolation (cf. Sect. 2.3), resulting in a loss of information at the split between unactivated interstitial aerosol and activated droplets (Fig. 3) for certain parameter combinations. A similar problem with local minima 
has been experienced in the inversion of bi-modal aerosol measurements (Helsper et al., 1982).

The strong non-linear interaction between the updraft and surface tension would also make inference of the single true calibration values very difficult. Nevertheless, the general shape of this response surface is logical based on our knowledge of the interactions of the parameters in question. The updraft is expected to compensate changes in the surface tension so that for higher updrafts, a higher surface tension is required to activate the same number of particles.

A response surface in which the gradient varies in a chaotic manner over the parameter space is presented in Figure $4 \mathrm{a}$ for marine Arctic conditions. It is observed that the chaotic and multi-modal nature of response surfaces decreases the more polluted the aerosol environment becomes (Fig. 4). The meteorological conditions remain the same between both simulations, and so it is the nature of the aerosol size distribution that results in these observed characteristics. This can be attributed to fact that the location of information content within the calibration data is stored over a smaller size range for cleaner aerosol environments which have narrower droplet size distributions (Fig. 3). For droplet size distributions with steeper gradients, small changes in the input parameters can lead to bigger "jumps" in the residual vector from one bin to the next, hence the OF varies in a more discontinuous manner. This potentially has a strong impact on the synthetically generated calibration data in which we give equal weighting to every bin.

Calibration parameter combinations which result in the calibration data set having a very narrow functional shape will further hamper a successful inversion by the necessary interpolation to a fixed size grid due to the moving centre model framework. This can be visualised from the response surfaces for marine Arctic conditions (Fig. 4a). A large region of the response surface contains very similar values of the OF. This is caused by the interpolation falling out of bounds of the narrow droplet distribution. This effect was also found for conditions in which the base updraft was very low $\left(0.1 \mathrm{~m} \mathrm{~s}^{-1}\right.$, figures not shown). In essence, parameter identifiability can deteriorate due to the interpolation, as widely varying parameter values result in very similar values of the OF. These findings are similar to those of Antilla and Kerminen (2007) who found the largest errors in their polynomial approximation in the presence of low updraft velocities that resulted in the droplet number changing sharply for changes in their input parameters.

This artefact of the interpolation will in turn make it more difficult for a search algorithm to find the appropriate parameter values. Therefore, our results suggest that a simple interpolation of the size distribution is not an ideal approach for applying inverse modeling to investigate cloud parcel models that employ a moving centre framework for clean clouds. To investigate this further we calculate the same response surface as in Fig. 5 of updraft versus the surface tension, although this time post-processing the droplet size distribution

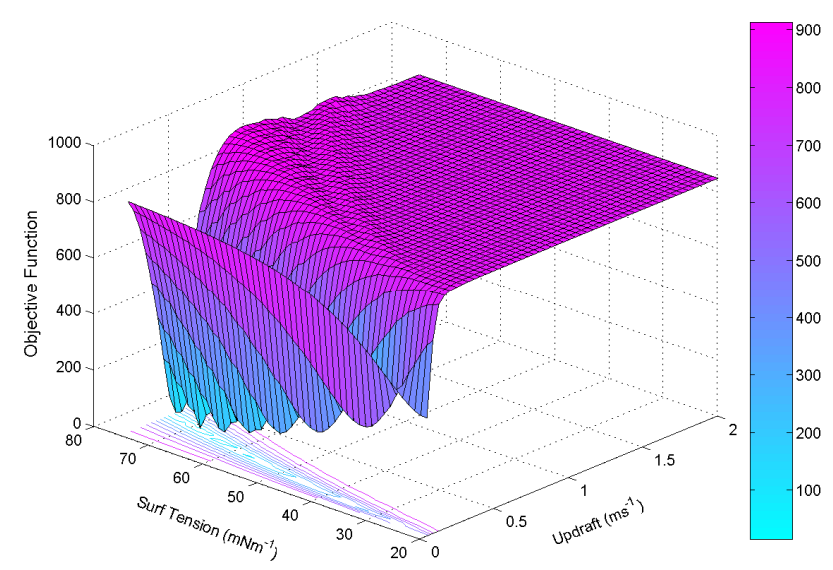

Fig. 5. Response surface of input updraft versus surface tension; colour of surface shows the change in gradient of the OF: marine average aerosol environment.

onto a fixed size grid using a simple re-binning procedure instead of interpolating (figure not shown). This was found to remove the local minima, providing a single broad minimum with a smooth gradient, since when the droplet distribution radius falls outside of the calibration data no information is lost. However, a re-binning approach reduces the amount of information in the calibration data set (the peak droplet number is concentrated over a few bins), meaning that the change in gradient of the OF near the optimal solution is vastly reduced compared to an interpolation approach. Thus, whilst a re-binning may slightly improve the convergence speed of an automatic search algorithm for clean aerosol environments it will impede convergence for polluted conditions for which the interpolation will be superior.

In summary:

- The identifiability of parameters controlling droplet activation for a pseudo-adiabatic cloud parcel model will be highly dependent on the prevailing aerosol environment.

- A significant number of parameters were found to be non-identifiable, or poorly constrained for all aerosol environments. These were the lognormal parameters describing the Aitken mode, and the mass accomodation coefficient.

- Many of the calibration parameters exhibit highly nonlinear parameter interactions. These correlations are expected to make the inference of single calibration parameter values very difficult.

- If certain parameters are held fixed, we are confident that the calibration of single optimal values for the key parameters of interest (soluble mass fraction and lognormal parameters describing the accumulation mode) using an automatic search algorithm can be successful 
without changing the current model structure or formulation of the OF.

- This inverse problem is made considerably more difficult by the moving centre output which does not lend itself to inverse modeling.

- It has been shown that the "smoothness" of the response surfaces is dependent on the initial updraft velocity and input aerosol size distribution.

\subsection{Objective Function: importance of location of infor- mation content-clean clouds versus polluted clouds}

It is useful to know how individual measurements constrain model parameters, and to determine the information content of the various observations. For the present study, the simplest way to identify the variation of the location of the information content of the calibration data (droplet size distribution) is to perform a sensitivity analysis on the $d N / d \log D_{\mathrm{p}}$ size distribution function over the entire particle size range available.

This serves two purposes; firstly it allows us to better understand the results from our response surface analysis, in turn allowing for a possible improvement to the OF definition. Secondly it shows the potential of inverse modeling for cloud parcel models when linking the model to actual measurements instead of using synthetic data. Combining response surface analysis with simple sensitivity analysis will allow us to determine over what size ranges it is most important to measure the cloud particle/droplet distribution with respect to aerosol physiochemical/meteorological parameters.

There are numerous ways to compare the sensitivities of the calibration data to different calibration parameters. The same approach as Šimůnek et al. (1998) is chosen, i.e. an increase of the calibration parameter values by a fixed percentage.

The sensitivity is calculated for each bin as:

$S_{d N / d \log d_{p, i}}(P+\Delta P)-d N / d \log d_{p, i}(P)$

$\Delta P=0.05 P$

where $S_{d N / d \log d_{p}}$ in Eq. (3) is the change in the wet droplet size distribution corresponding to a $5 \%$ change in parameter $P$ by $\Delta P$. We used a one-sided approach, in which parameter sensitivities are determined by perturbing the reference set by $+5 \%$. A centred sensitivity analysis approach, in which the outcome of a positive and negative parameter perturbation are averaged, yielded very similar results.

In the calculation of the $\mathrm{OF}$, the vector of residuals is calculated between data points corresponding to bin numbers for the $d N / d \log D_{\mathrm{p}}$ size distribution function. Therefore, in the following plots, to allow a consistent analysis of the information content at each bin point (each having equal weighting), the sensitivity figures are plotted against bin number instead of radius. To retain information on the change in sensitivity with respect to size we also overlay the particle radius versus bin number.

So far we have presented response surface analysis for when the OF only includes activated droplets, thus the focus of this section will be on the advantages of including the interstitial aerosol in the calibration data set. From the ten possible calibration parameters, a sensitivity analysis will be provided for a selection of five calibration parameters to address the issues raised in the previous section. These parameters are the aerosol number concentration in the Aitken and accumulation modes, the aerosol radius in the accumulation mode, the updraft and the soluble mass fraction. The results for two of the four aerosol environments, marine average and rural continental conditions are presented in Fig. 6.

Firstly it can be seen that the interstitial aerosol is most sensitive to a perturbation of the Aitken mode aerosol concentration. This is expected as these smaller Aitken mode particles are less easily activated into cloud droplets. For the rural continental environment (Fig. 6b) the sensitivity is larger than the marine average case (Fig. 6a) as there are more particles in the interstitial aerosol within the calibration data (it is already CCN saturated). From this it can be deduced that the improvement in identifiability of the lognormal parameters describing Aitken mode aerosol depends on the $\mathrm{CCN}$ saturation of the aerosol environment.

A perturbation of the mean radius of the particles in the accumulation mode results in a shift in the size distribution towards larger sizes as well as an increase in concentration of largest droplets/decrease in concentration of smaller droplets. This is due to the larger particles growing on the expense of the smaller particles, leaving them unactivated.

The interstitial aerosol is not sensitive to an increase in either the accumulation mode radius or concentration. Therefore, for these two parameters little information will be added to the $\mathrm{OF}$ by including the interstitial aerosol in the calibration data.

When the updraft is perturbed by $5 \%$ the impact for the marine average environment (Fig. 6a) is most visible in the droplet size range larger than $1 \mu \mathrm{m}$ radius. This is understandable since the physical structure of pseudo-adiabatic cloud parcel model running with constant updraft velocity is such that in the absence of entrainment/mixing processes, a decrease in the required critical supersaturation $\left(S^{*}\right)$ by increasing the updraft velocity $(v)$ will monotonically increase the total number of droplets $\left(N_{\mathrm{d}}\right)$ until all of the particles become activated; $N_{\mathrm{d}}=f\left(S^{*}\right)=f\left(v, d N_{\mathrm{a}} / d \log d_{\mathrm{p}}\right)$.

The change in soluble mass fraction results in an increase in the number of smaller activated droplets and reduction in the number of larger droplets. For the rural continental case the shape of the sensitivity of the droplet size distribution to updraft and soluble mass fraction (Fig. 6b) is the same as for marine average conditions. However, as the base case contains a greater number of larger particles, increasing the updraft and soluble mass fraction has less impact compared to 


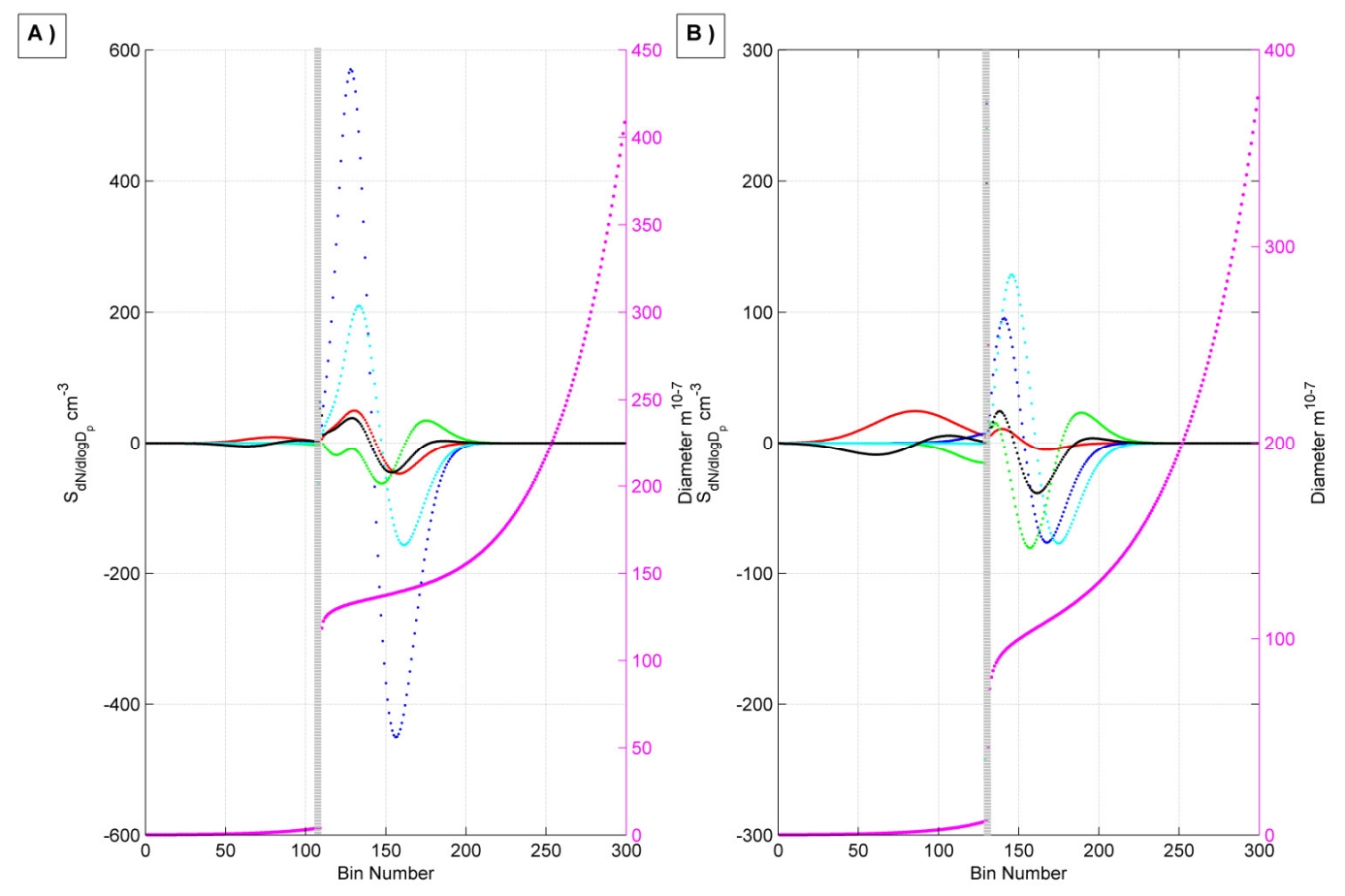

Fig. 6. (A-B) Pertubations in particle number caused by a $5 \%$ increase in input parameters: red dotted line - Aitken mode number concentration, blue dotted line - accumulation mode number concentration, green dotted line - accumulation mode radius, cyan dotted line updraft velocity, black dotted line - soluble mass fraction. Grey dashed vertical line represents the break between interstital and activated droplets: magenta line - represents particle diameter. (A) marine average aerosol environment, (B) rural continental aerosol environment.

the cleaner marine average environment as it is already $\mathrm{CCN}$ saturated. This will be examined in more detail in our susceptibility analysis (cf. Sect. 3.4). For the more polluted rural continental aerosol environment the difference in sensitivity between the soluble mass fraction and accumulation mode number is reduced, highlighting an increased relative importance of the chemistry. For rural continental conditions, a higher sensitivity of the interstitial aerosol to a change in soluble mass fraction compared to the marine environment is evident.

\subsubsection{Implications for measurements}

Including the interstitial aerosol in the calibration data set will only be advantageous if we wish to explore the lognormal parameters describing the Aitken mode or the soluble mass fraction for $\mathrm{CCN}$ saturated aerosol environments. This illustrates the importance of better measurements of the interstitial aerosol concentrations for polluted environments, as higher quality observations will more closely constrain the respective pseudo-adiabatic cloud parcel model parameter values considered herein. For aerosol environments that are polluted, the droplet size distribution is observed to be more susceptible to the changes in the chemistry (represented by the soluble mass fraction) than parameters describing the lognormal aerosol size distribution. This highlights the im- portance of the composition of the dry aerosol size distribution. For the current updraft, the five parameters investigated in Sect. 3.2 for marine average conditions are generally more excitable compared to rural continental environments. This indicates that cleaner conditions will be easier to constrain using inverse modeling methods. However, the size range over which the droplet distribution is sensitive is much narrower, indicating the need for higher resolution of droplet size distribution measurements than are currently available from standard forward scattering spectrometer probe (FSSP) probes (cf. Sect. 3.2.2).

\subsubsection{Implications for models}

The narrowness of the parameter sensitivity with respect to droplet size for marine average conditions explains our chaotic response surfaces (cf. Sect. 3.1) as the gradient of the calibration data set changes very sharply between different simulations. The smoothness of the transition from interstitial aerosol to activated droplets, thus also the smoothness of our response surfaces could be improved by developing the approach to determine the fraction of activated particles (Takeda and Kuba, 1982; Korhonen et al., 2005) or by employing an adaptive spectrum refinement procedure such as the one developed by Arabas and Pawlowska (2011). Alternatively, developing fixed sectional cloud parcel models 
which avoid the drawbacks of numerical diffusion (Lehtinen and Kulmala, 2003) has the potential to avoid some of the issues discussed in Sect. 3.1. One further potential improvement would be to weigh the model output in an appropriate manner. This was shown to have a large impact on wavelength experiments by Cochran and Horne (1977). There are numerous possible weighting methods, and a weighting technique has been used successfully in the determination of narrow aerosol size distribution measurements (Voutilainen et al., 2000). Unfortunately this is no simple task when using synthetic calibration data to study parameter sensitivity for a simple pseudo-adiabatic parcel model, as there is no variation in time with which to apply the weighting, and if an arbitrary weighting is applied to obtain a smoothing it becomes very easy to bias the results. Also such a weighting may not be successful for all aerosol environments. An alternative would be to utilize a wavelet representation of the functional data, as this has been found to be a useful approach for problems in which the data is very "spiky" (Bayarri et al., 2006).

\subsection{Improving the information content of the OF}

Research into the data requirements for successful application of inverse methods reveals that the information content of the data used for calibration is far more important than the quantity (resolution) of the data (Kuczera, 1982; Sorooshian et al., 1983; Sorooshian and Gupta, 1985; Yapo et al., 1996; Gupta et al., 1998; Vrugt et al., 2001). In light of this we now recalculate a response surface for the Aitken mode number concentration versus the updraft velocity and soluble mass fraction (Fig. 7a, c) for rural continental aerosol environment. We then repeat the calculations and include the entire size distribution function in the calibration data to confirm that the identifiability of the aerosol concentration in the Aitken mode could be improved by including the interstitial aerosol (cf. Sect. 3.2). It is clear that for both environments, if interstitial particles are included the solution becomes more identifiable (Fig. 7b, d).

Another possible method of adding more information would be to add extra cloud height levels to the calibration data. The use of data from multiple heights will potentially improve our model parameterization, yet will pose difficulties during calibration. The increased dimensionality of the parameter space will likely increase parameter uncertainty and correlation. Tests were performed for marine conditions by adding the output at $20 \mathrm{~m}, 50 \mathrm{~m}$ and $200 \mathrm{~m}$ above cloud base (figures not shown). Our results demonstrate that the model parameter values became better identified, but the improvement was somewhat modest. This is not surprising since for this model set up, the processes of entrainment and collision-coalescence were deactivated; therefore, the number of activated droplets initially changes as a step function with height above cloud base, but then remain constant. The
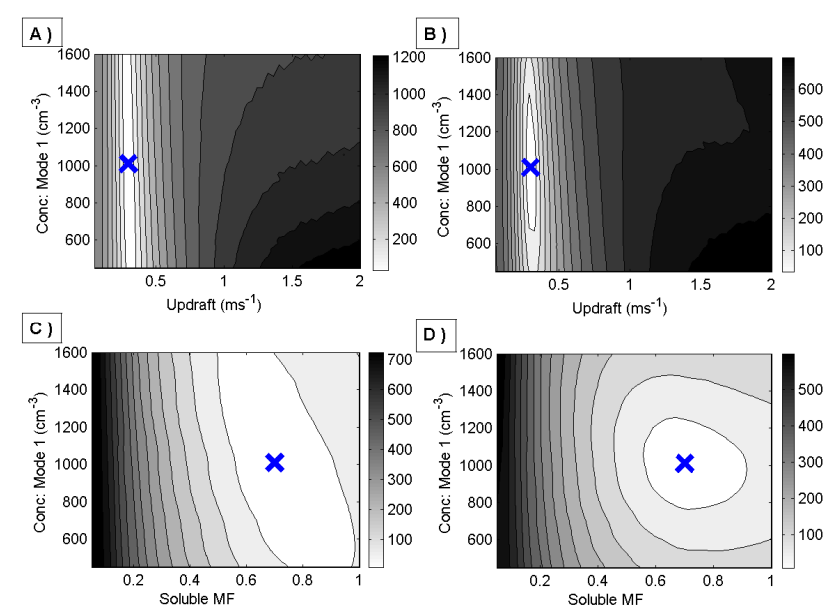

Fig. 7. (A-D) 2-D response surf ace planes for a selection of two parameter combinations. The blue cross denotes the true parameter values used to generate the synthetic measurements. Greyscale shows the change in gradient of the OF: $(\mathbf{A}, \mathbf{C})$ rural continental aerosol environment (only activated particles), (B, D) rural continental aerosol environment (including interstitial aerosol).

only additional information will be that of the size of the particles.

An alternative definition of the OF explored for cloud parcel models that employ a moving centre description of droplet activation that avoids the problems associated with interpolating or re-binning (cf. Sect. 3.1) is to explicitly include both the number and associated radius components of the size distribution in the calibration data. This methodology involves including vectors of both the $\mathrm{x}$ - and $\mathrm{y}$ components of the droplet size distribution in one OF. Thus, our vector of model predictions, $\boldsymbol{Y}=\{y 1, \ldots, y n ; x 1, \ldots, x n\}$ consists of a joint vector of $\log \left(d N / d \log D_{\mathrm{p}}\right)$ and $\log \left(D_{\mathrm{p}}\right)$ values. By explicitly including the radius values we negate the need to interpolate the model output to a fix grid, thus bypassing any loss of information. This OF was found to provide smooth and generally well defined response surfaces. Tests show this will facilitate the efficient solution of a higher dimensional inverse problem; however, more work is required to derive a weighting for the individual $\mathrm{x}$ - and $\mathrm{y}$-components as they each have different units.

\subsection{Response surface analysis: droplet size distribution susceptibility analysis}

Here we use the term droplet size distribution susceptibility to illustrate how sensitive the modelled cloud droplet size distribution is to different calibration parameters. The white regions of response surfaces highlight parameter combinations for which the difference between the calibration data (generated from the values indicated by the blue cross), and a droplet size distribution generated with a different parameter combination are very small, i.e. OF values are low. The 

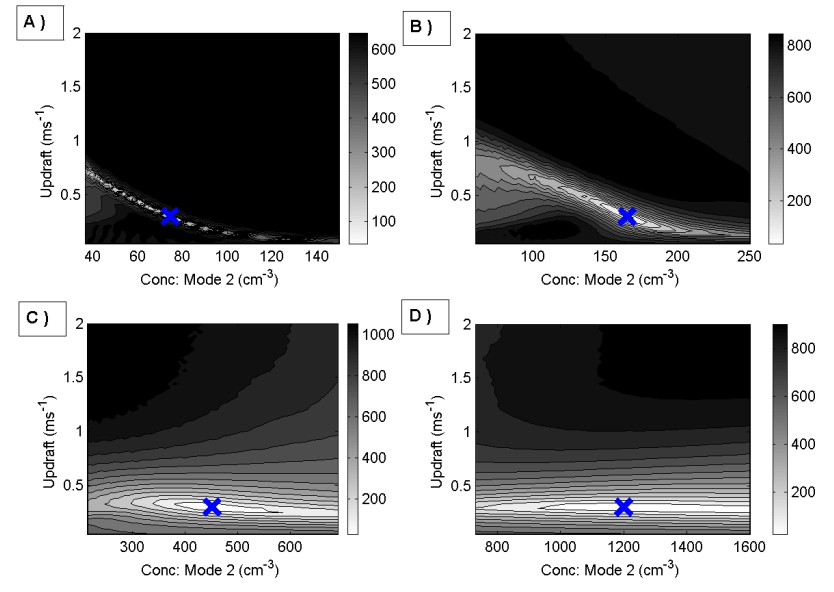

Fig. 8. (A-D) 2-D response surface planes for a selection of two parameter combinations. The blue cross denotes the true parameter values used to generate the synthetic measurements. Greyscale shows the change in gradient of the OF which provides a measure of droplet size distribution susceptibility: (A) marine Arctic;

(B) marine average; (C) rural continental; (D) polluted continental.

reason for this can be attributed either to the fact the droplet size distribution is not sensitive to changes in a particular parameter or there are compensating effects between different processes in the cloud parcel model. It is worth noting that these results only represent susceptibility of droplet size distribution, and could be repeated for any number of observations. For instance it is likely that a calibration dataset containing the third moment of the droplet size distribution (proportional to LWC) will result in a different response surface, and susceptibility. Base selections of three response surfaces have been chosen to represent the key parameters of interest with respect to droplet size distribution susceptibility for different aerosol environments.

\subsubsection{Marine Arctic aerosol environment}

The susceptibility of the droplet size distribution to both the updraft velocity and the concentration of accumulation mode particles for a clean marine Arctic aerosol environment are presented in Fig. 8a. It is clear that the droplet size distribution is far more sensitive to changes in the updraft velocity than particle concentration in the accumulation mode. It is also evident from this response surface that the relationship between the updraft and concentration is non-linear, such that lower particle concentrations are compensated by increasing the updraft velocity. The narrowness of the white region shows that there is very little freedom before entering a new regime of cloud properties (shown by the regions of the response surface with higher $\mathrm{OF}$ values). The response surface of the updraft velocity versus the chemistry (soluble mass fraction) (Fig. 9a) for marine Arctic conditions illustrates a very similar pattern. The relationship between the soluble
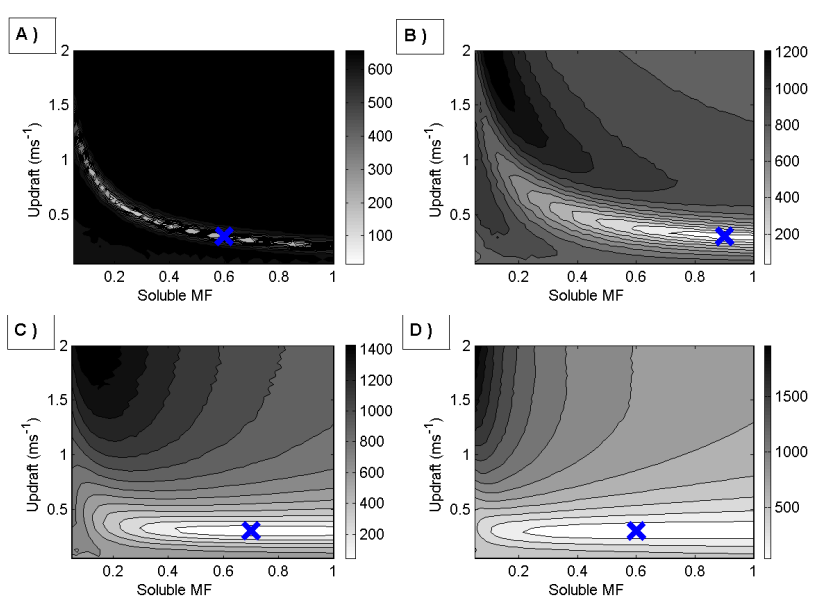

Fig. 9. (A-D) 2-D response surface planes for a selection of two parameter combinations. The blue cross denotes the true parameter values used to generate the synthetic measurements. Greyscale shows the change in gradient of the OF which provides a measure of droplet size distribution susceptibility: (A) marine Arctic;

(B) marine average; (C) rural continental; (D) polluted continental.

mass fraction and updraft velocity is highly non-linear. Reductions in the soluble mass fraction are permitted if they are compensated by a simultaneous increase in the updraft velocity. The only difference in replacing the particle concentration with the soluble mass fraction is that the relationship with respect to the updraft has a stronger gradient i.e. a larger increase in updraft is required to compensate the same fractional reduction in soluble mass fraction compared to particle concentration (Fig. 8a). Similarly, with yet a stronger gradient, it is possible to compensate a reduction in the soluble mass fraction by an increase in the concentration of accumulation mode particles (Fig. 10a). In reality, however, one should keep in mind that a soluble mass fraction of 0.2 is highly unlikely in the marine environment. By looking only at the range $0.5-1.0$ it is clear that the droplet size distribution is more susceptible to changes in the concentration of accumulation mode particles in this CCN limited environment than changes in the chemistry.

\subsubsection{Marine average aerosol environment}

The susceptibility of the droplet size distribution to the updraft velocity versus the concentration of the accumulation mode particles for a marine average aerosol environment is presented in Fig. 8b. The concentration of accumulation mode particles used to generate the droplet size distribution is approximately twice that of the very clean marine Arctic environment (Fig. 8a).

As for marine Arctic conditions, the droplet size distribution is more sensitive to changes in the updraft velocity than particle concentration in the accumulation mode and the relationship between the updraft and concentration is also 
non-linear. However, the regime is less sensitive to changes in the updraft compared to marine Arctic conditions shown by the reduced gradient of the change in OF from the true value in the y-plane of the response surface. It is also possible to produce very similar OF values of the droplet size distribution for a larger range of updrafts at a given particle concentration. The lower limit of particle concentration at which a very similar droplet size distribution can be generated is also higher than for marine Arctic conditions. This means that regardless of the increase in updraft, it is no possible to very closely match the calibration data when the particle concentration is reduced below $100 \mathrm{~cm}^{-3}$. This region is thus limited by the number of particles, while on the opposite end of the spectrum, when the number is above $200 \mathrm{~cm}^{-3}$ the air is so CCN saturated it cannot be compensated by a decrease in the updraft velocity. The strong slope in-between these extremes indicate a regime between $\mathrm{CCN}$-limited and $\mathrm{CCN}$-saturated conditions, where compensating effects may produce almost identical droplet distributions as in the base case.

The response surface of the updraft velocity versus the chemistry (soluble mass fraction) (Fig. 9b) for marine average conditions illustrates a very similar pattern to marine Arctic conditions (Fig. 9a), and the differences between the two are similar to those observed for accumulation mode number concentration. The droplet size distribution is less sensitive to updraft changes, and the ability for the updraft to compensate a decrease in the soluble mass fraction to achieve the same droplet size distribution is reduced. Nevertheless, particle number is still more important than the chemistry, and updraft is more important than both of these for accurately reproducing the observed droplet size distribution. This conclusion is supported by Fig. 10b in which we see that, as for marine Arctic conditions accumulation mode particle concentration can compensate a reduction in soluble mass fraction. Compared to marine Arctic conditions the gradient change in OF over the y-plane is reduced and the bounds representing susceptibility to concentration are increased (a wider white region in the y-plane showing a reduction in susceptibility).

\subsubsection{Rural continental aerosol environment}

Moving to a more polluted environment, a significant regime shift in the number of available CCN compared to the previous marine Arctic and marine average conditions results in a distinct difference in the shape of the response surfaces. Even with a significant reduction of accumulation mode particle concentration (Fig. 8c) the existing reservoir of particles available in the interstitial aerosol are sufficient to result in the same droplet size distribution with only minor variations in the updraft velocity. This is indicated by yet a further reduction of the rate of decrease in the OF across the y-plane from the true parameter value compared to the cleaner environments previously presented. A greater change in meteo-
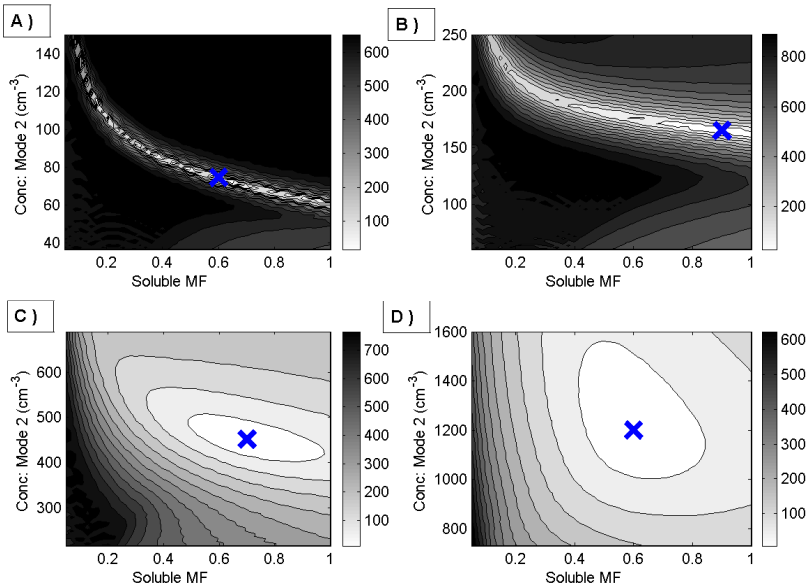

Fig. 10. (A-D) 2-D response surface planes for a selection of two parameter combinations. The blue cross denotes the true parameter values used to generate the synthetic measurements. Greyscale shows the change in gradient of the OF which provides a measure of droplet size distribution susceptibility: (A) marine Arctic;

(B) marine average; (C) rural continental; (D) polluted continental.

rological conditions is necessary to evoke a change in cloud properties, indicating this environment exhibits lower susceptibility to changes in updraft. The response surface of the updraft velocity versus the chemistry (Fig. 9c) for rural continental conditions also has a reduced gradient.

The same can be said for when the updraft is replaced by the concentration of accumulation mode particles (Fig. 10c). As the environment is already $\mathrm{CCN}$ saturated regardless of how much the accumulation mode number concentration is increased it cannot compensate values of the soluble mass fraction below 0.3

The distinctly different parameter relationships and droplet size distribution susceptibility for this more polluted case indicates that there is a tipping point in the sensitivity and dominant processes for droplet activation somewhere between marine average and rural continental conditions.

\subsubsection{Polluted continental aerosol environment}

Sensitivity to particle concentration and soluble mass fraction with respect to the updraft velocity reduces even further for polluted continental environments as shown in Figs. 8d and $9 \mathrm{~d}$. In this highly $\mathrm{CCN}$ saturated environment the sensitivity to the concentration of accumulation mode particles does not dominate the chemistry (Fig. 10d).

\subsubsection{Summary}

Distinct changes in parameter sensitivity with changes in the number of available $\mathrm{CCN}$ provides information regarding how droplet size distribution susceptibility to different parameters will vary for different locations. As shown in 
Figs. 8-10 that there is a tipping point between marine average and rural continental aerosol conditions for parameters most important for controlling droplet activation. For all environments the most important parameter is the updraft velocity and the droplet size distribution is most susceptible to changes in parameter values for the cleanest marine Arctic aerosol environment. The non-linearity of the parameter interaction is stronger for the two cleaner aerosol environments. It is clear for every aerosol environment that clouds are mulit-dimensional problems that may have a plethora of possible solutions based on an inverse analysis. The strong interaction between different calibration parameters involved in cloud droplet activation highlights the need to apply MCMC methods to treat the interaction between all parameters simultaneously.

\section{Monte Carlo (MC) parameter sampling and automatic model calibration}

As it has been is shown that the "cloud-aerosol" inverse problem will be difficult to solve (cf. Sect. 3.1) in this section we will demonstrate the advantages of embracing automatic search algorithms with the aid of response surfaces. To demonstrate this, results of a standard Latin hypercube sampling (LHS) MC simulation will be compared with a deterministic optimisation algorithm: the Shuffled Complex Evolution global optimisation algorithm (SCE-UA) (Duan et al., 1992).

A simple MC based approach can only give an estimate of the global optimum solution, whereas a search algorithm such as SCE-UA is designed to find the minimum value of the $\mathrm{OF}$ in a minimum number of function evaluations. The success of these two different search methods can be visually demonstrated by marking onto the response surfaces which solutions have been visited by each individual method.

The determination of the global minimum of the OF will become increasingly difficult with increasing dimensionality of the parameter space. It is inevitable that with such a limited data set, some of our calibration parameters will require fixing prior to optimisation (cf. Sect. 3.1). Based on the knowledge gained from our response surfaces analysis, we fixed the values of the surface tension, and updraft, both known to be highly multi-modal, to their known (true) values. We also fixed the lognormal parameters describing the Aitken mode, as they were deemed non-identifiable (Sect. 3.1). Altogether, this leaves us with four "unknown" parameters for optimization.

The various solutions that have been created from a standard LH sampling simulation are overlaid onto the response surface of accumulation mode concentration versus soluble mass fraction for marine average and rural continental conditions respectively (Fig. 11a-b). The green dots represent the lowest $10 \%$ of the OF values from 5000 different MC realizations. Each dot corresponds to a different parameter combination. A brute force MC approach is not only inefficient, but potentially also misleading. If we draw inferences based on this set of 5000 different solutions, then our ensemble of best solutions is still significantly different from the actual optimum solution (blue cross). The solutions exhibit significant scatter, and even after 5000 trials not a single parameter set can be found that finds the optimum perfectly. In comparison the superior efficiency of the automatic search algorithm is indicated by the best $10 \%$ of the SCE-UA simulations, as shown by the red dots being located densely over the true optimal solution for each response surface. Fortunately, the pseudo-adiabatic cloud model used herein is computationally efficient. Nevertheless, our findings illustrate the need for a sophisticated search algorithm that, within a small number of function evaluations can efficiently and effectively explore the parameter space.

When the simulations were repeated with five parameters by including the updraft velocity the level of success of the SCE-UA algorithm deteriorated. This is attributed to the presence of strong non-linear parameter interaction and numerous local optima within the response surfaces (solutions within the parameter space which have virtually identical objective function values), both characteristic of our response surfaces (cf. Sects. 3.1-3.4). This highlights the need for powerful global optimization methods, such as SCE-UA or AMALGAM-SO (Vrugt et al., 2009b) that use a population of points (parameter values) and seek iterative improvement using the information contained in this sample. Single chain MCMC methods which are known to struggle when confronted with multiple regions of attraction and prone to premature convergence in a local basin of attraction en route to the global optimum may be inadequate for studying the cloud-aerosol inverse problem.

\section{Conclusions}

In this paper, by using a response surface analysis to gain a visual understanding of the behaviour of the $\mathrm{OF}$ in the parameter space we have explored the susceptibility of cloud droplet size distributions to changes in aerosol physiochem$\mathrm{ical} /$ meteorological parameters, as well as the feasibility of inverse modeling for estimating the parameters of adiabatic cloud parcel models. This analysis reveals important information about droplet size distribution susceptibility and identifiability of the pseudo-adiabatic cloud parcel model parameters with respect to the information content of the calibration data, and how this varies depending on four distinctly different aerosol environments.

From our droplet size distribution susceptibility analysis it was found that clean marine Arctic environments are far more sensitive to perturbations in both aerosol and meteorological parameters than polluted continental environments that are already $\mathrm{CCN}$ saturated. A reduction in particle emissions will have a smaller effect on the cloud microphysical 

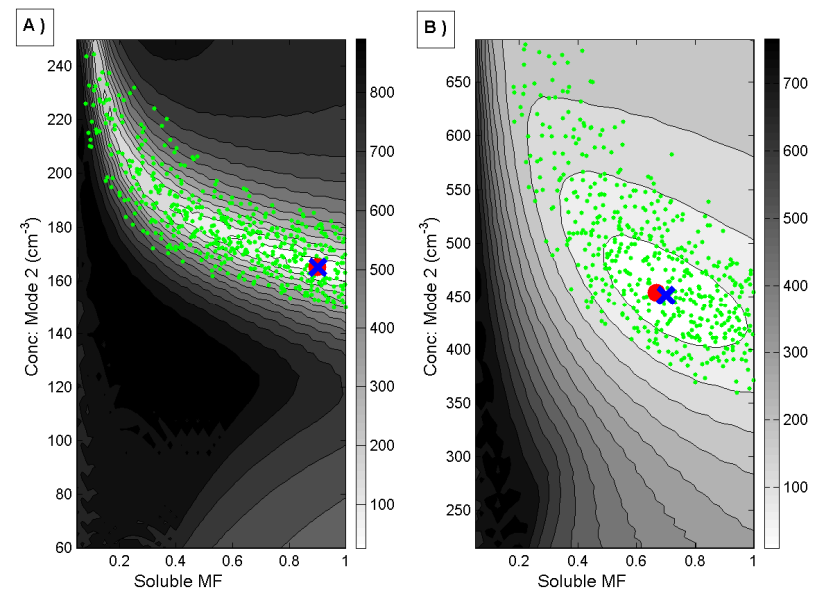

Fig. 11. (A-B) $10 \%$ lowest solutions from 5000 LHS Monte Carlo simulations (green dots) overlaid on a 2-D response surface for one selected parameter pair. Red dot shows the $10 \%$ lowest solutions from the SCE-UA optimisation algorithm. The blue cross denotes the true parameter values used to generate the synthetic measurements. Greyscale shows the change in gradient of the OF: (A) marine average aerosol conditions, (B) rural continental aerosol conditions.

properties for polluted regions, while clean regions such as marine average and marine Arctic environments are much more responsive to changes in aerosol physiochemical properties and abundance. This highlights the need to focus future measurement campaigns in very clean aerosol environments.

Response surfaces show that the non-identifiable nature of the lognormal parameters describing the Aitken aerosol mode means that these parameters will need fixing to their true values for the determination of the global minimum of the OF by an optimisation algorithm, unless the interstitial aerosol is included in the calibration data. It was also shown with the aid of a simple sensitivity analysis that to constrain the solution to the cloud- aerosol inverse problem for polluted environments it is advantageous to perform measurements of the interstitial aerosol, as very similar droplet distributions can be achieved for a range of parameter values.

When using synthetically generated data to study parameter sensitivity the required interpolation of the raw model output for very narrow droplet size distributions can deteriorate parameter identifiability as widely varying parameter values result in very similar values of the OF. This creates difficulties for any optimisation algorithm, and this impact is stronger for cleaner clouds than for polluted clouds.

Cloud models are highly parameterized, becoming increasingly complex, and containing more and more input parameters. They are also highly non-linear due to the evolving nature of an aerosol size distribution into a cloud droplet size distribution. From our analysis it has been shown that whilst these qualities mean that the cloud-aerosol inverse problem will be particularly difficult to solve. Global sensitivity meth- ods that can treat interaction between all parameters simultaneously are important if we wish to fully understand the complex nature of cloud-aerosol interactions for different aerosol-meteorological environments.

The scope of our future research will be to apply MCMC methods for inference of the posterior probability density function of the parameters. This method belongs to the class of MCMC methods (Bayesian statistics) that not only provide an estimate of the best parameter values, but also a sample set of the underlying (posterior) uncertainty. This distribution contains all the desired information about parameter sensitivity, interaction and correlation, and can be used to produce confidence intervals on the model predictions. In particular, in a subsequent paper (Part 2) we will use use the recently developed DiffeRential Evolution Adaptive Metropolis (DREAM) MCMC algorithm (Vrugt et al., 2009a) with synthetic data to benchmark its performance, and test the parameter estimates of the pseudo-adiabatic cloud model and their nonlinear uncertainty and correlation.

Acknowledgements. We gratefully acknowledge the financial support of the Bert Bolin Centre for Climate research. We gratefully appreciate G. J. Roelofs, IMAU, Utrecht, the Netherlands, for providing us with the pseudo-adiabatic cloud parcel model used in this study. We gratefully acknowledge Hamish Struthers valuable discussions and his help to improve the readability of the manuscript. Some of the calculations made during the course of this study have been made possible using the LISA cluster from the SARA centre for parallel computing at the University of Amsterdam, the Netherlands. AS acknowledges support from an Office of Naval Research YIP award (N00014-10-1-0811).The authors acknowledge the Swedish Environmental Monitoring Program and Naturvårdsverket (Swedish environmental protection agency).

Edited by: V.-M. Kerminen

\section{References}

Andreae, M. O. and Rosenfeld, D.: Aerosol-cloud-precipitation interactions. Part 1. The nature and sources of cloud-active aerosols, Earth Sci. Rev., 89, 13-41, 2008.

Anttila, T. and Kerminen, V.-M.: On the contribution of Aitken mode particles to cloud droplet populations at continental background areas - a parametric sensitivity study, Atmos. Chem. Phys., 7, 4625-4637, doi:10.5194/acp-7-4625-2007, 2007.

Ayers, G. P. and Larson T. V.: Numerical study of droplet size dependent chemistry in oceanic, wintertime, stratus cloud at southern midlattitudes, J. Atmos. Chem., 11(1-2), 143-167, 1990.

Arabas, S. and Pawlowska, H.: Adaptive method of lines for multi-component aerosol condensational growth and $\mathrm{CCN}$ activation, Geosci. Model Dev., 4, 15-31, doi:10.5194/gmd-4-152011, 2011.

Bayarri, M., Berger, J., Garcia-Donato, G., Liu, F., Palomo, J., Paulo, R., Sacks, J., Walsh, D., Cafeo, J., and Parthasarathy, R.: Computer Model Validation with Functional Outputs. Tech. rep., arXiv.org, math.ST, 2006. 
Beven, K.: A manifesto for the equifinality thesis, J. Hydrol., 320(1-2), 18-36, 2006.

Bikowski, J., van der Kruk, J., Huisman, J. A., Vereecken, H., and Vrugt, J. A.: Inversion and sensitivity analysis of GPR data with waveguide dispersion using Markov Chain Monte Carlo simulation, Ground Penetrating Radar (GPR), 13th International Conference, 2010.

Birmili, W., Wiedensohler, A., Heintzenberg, J., and Lehmann, K.: Atmospheric particle number size distribution in Central Europe: statistical relations to air masses and meteorology, J. Geophys. Res., 106, 32005-32018, doi:10.1029/2000JD000220, 2001.

Cochran, R. N. and Horne, F. H.: Statistically weighted principle component analysis of rapid scanning wavelength kinetics experiments, Anal. Chem., 49(6), 846-853, 1977.

Conant, W. C., VanReken, T. M., Rissman, T. A., Varutbangkul, V., Jonsson, H. H., Nenes, A., Jimenez, J. L., Delia, A. E., Bahreini, R., Roberts, G. C., Flagan, R. C., and Seinfeld, J. H.: Aerosol, cloud drop concentration closure in warm cumulus, J. Geophys. Res., 109(D13), D13204, doi:10.1029/2003JD004324, 2004.

Cressie, N., Calder, C. A., Clark, J. S., Hoef, J. M. V., and Wikle, C. K.: Accounting for uncertainty in ecological analysis: the strengths and limitations of hierarchical statistical modeling, Ecol Appl., 19(3), 553-570, 2009.

Crump, J. G. and Seinfeld J. H.: A New Algorithm for Inversion of Aerosol Size Distribution Data, Aerosol Sci. Tech., 1(1), 15-34, 1982.

Duan, Q. Y., Sorooshian, S., and Gupta, V.: Effective and Efficient Global Optimization for Conceptual Rainfall-Runoff Models, Water Resour. Res., 28(4), 1015-1031, 1992.

Duan, Q. Y., Gupta, V. K., and Sorooshian S.: Shuffled Complex Evolution Approach for Effective and Efficient Global Minimization, Journal of Optimization Theory and Applications, 76(3), 501-521, 1993.

Dusek, U., Frank, G. P., Hildebrandt, L., Curtius, J., Schneider, J., Walter, S., Chand, D., Drewnick, F., Hings, S., Jung, D., Borrmann, S., and Andreae, M. O.: Size matters more than chemistry for cloud-nucleating ability of aerosol particles, Science, 312(5778), 1375-1378, 2006.

Feingold, G.: Modeling of the first indirect effect: Analysis of measurement requirements, Geophys. Res. Lett., 30(19), 1997, doi:10.1029/2003GL017967, 2003.

Fitzgerald, J. W.: Effect of aerosol composition on cloud droplet size distribution - numerical study, J. Atmos. Sci., 31, 13581367, 1974.

Gupta, H. V., Sorooshian, S., and Yapo P. O.: Toward improved calibration of hydrologic models: Multiple and noncommensurable measures of information, Water Resour. Res., 34(4), 751-763, 1998.

Gupta, H. V., Wagener, T., and Liu, Y. Q.: Reconciling theory with observations: elements of a diagnostic approach to model evaluation, Hydrol. Process., 22(18), 3802-3813, 2008.

Hänel, G.: The role of aerosol properties during the condensational stage of cloud: a reinvestigation of numerics and microphysics, Beitr. Phys. Atmosph., 60, 321-339, 1987.

Hegg D. A. and Larson T. V.: The effects of microphysical parameterisation on model predictions of sulfate production in clouds, Tellus, 42B, 272-284, 1990.

Heintzenberg, J., Covert, D. C., and Van Dingenen, R.: Size distribution and chemical composition of marine aerosols: a compila- tion and review, Tellus B, 52(4), 1104-1122, 2000.

Helsper, C., Fissan, H., Kapadia, A., and Liu, B. Y. H.: Data Inversion by simplex minimization for the electrical aerosol analyzer, Aerosol Sci. Tech. 1, 135-146, 1982.

Hsieh, W. C., Nenes, A., Flagan, R. C., Seinfeld, J. H., Buzorius, G., and Jonsson, H.: Parameterization of cloud droplet size distributions: Comparison with parcel models and observations, J. Geophys. Res., 114, D11205, doi:10.1029/2008JD011387, 2009.

IPCC: Climate Change: Summary for Policymakers. The Physical Science Basis, Contribution of Working Group I to the Fourth Assessment Report of the Intergovernmental Panel on Climate Change, edited by: Solomon, S., Qin, D., Manning, M., Chen, Z., Marquis, M., Averyt, K. M., and Tignor, H. M., New York, Cambridge Univ. Press, 2007.

Jacobson, M. Z.: Development and application of a new air pollution modeling system-II. Aerosol model structure and design, Atmos. Environ., 31, 131-144, 1997.

Järvinen, H., Räisänen, P., Laine, M., Tamminen, J., Ilin, A., Oja, E., Solonen, A., and Haario, H.: Estimation of ECHAM5 climate model closure parameters with adaptive MCMC, Atmos. Chem. Phys., 10, 9993-10002, doi:10.5194/acp-10-9993-2010, 2010.

Kanakidou, M., Seinfeld, J. H., Pandis, S. N., Barnes, I., Dentener, F. J., Facchini, M. C., Van Dingenen, R., Ervens, B., Nenes, A., Nielsen, C. J., Swietlicki, E., Putaud, J. P., Balkanski, Y., Fuzzi, S., Horth, J., Moortgat, G. K., Winterhalter, R., Myhre, C. E. L., Tsigaridis, K., Vignati, E., Stephanou, E. G., and Wilson, J.: Organic aerosol and global climate modelling: a review, Atmos. Chem. Phys., 5, 1053-1123, doi:10.5194/acp-5-1053-2005, 2005.

Kandlikar, M. and Ramachandran G.: Inverse methods for analysing aerosol spectrometer measurements: A critical review, J. Aerosol Sci., 30(4), 413-437, 1999.

Köhler, H.: The nucleus in and the growth of hygroscopic droplets, Trans. Faraday Soc., 32, 1152-1161, 1936.

Korhonen, H., Kerminen, V.-M., Lehtinen, K. E. J., and Kulmala, M.: CCN activation and cloud processing in sectional aerosol models with low size resolution, Atmos. Chem. Phys., 5, 25612570, doi:10.5194/acp-5-2561-2005, 2005.

Kuczera, G.: On the Relationship between the Reliability of Parameter Estimates and Hydrologic Time-Series Data Used in Calibration, Water Resour. Res., 18(1), 146-154, 1982.

Laaksonen, A., Korhonen, P., Kulmala, M., and Charlson R. J.: Modification of the Köhler equation to include soluble trace gases and slightly soluble substances, J. Atmos. Sci., 55(5), 853$862,1998$.

Laine, M. and Tamminen, J.: Aerosol model selection and uncertainty modelling by adaptive MCMC technique, Atmos. Chem. Phys., 8, 7697-7707, doi:10.5194/acp-8-7697-2008, 2008.

Lance, S., Nenes, A., and Rissman T. A.: Chemical and dynamical effects on cloud droplet number: Implications for estimates of the aerosol indirect effect, J. Geophys. Res., 109, D22208, doi:10.1029/2004JD004596, 2004.

Lehtinen, K. E. J. and Kulmala, M.: A model for particle formation and growth in the atmosphere with molecular resolution in size, Atmos. Chem. Phys., 3, 251-257, doi:10.5194/acp-3-251-2003, 2003.

Lohmann, U. and Feichter, J.: Global indirect aerosol effects: a review, Atmos. Chem. Phys., 5, 715-737, doi:10.5194/acp-5-7152005, 2005. 
Loridan, T., Grimmond, C. S. B., Grossman-Clarke, S., Chen, F., Tewari, M., Manning, K., Martilli, A., Kusaka, H., and Best, M.: Trade-offs and responsiveness of the single-layer urban canopy parameterization in WRF: an offline evaluation using the MOSCEM optimization algorithm and field observations, Q. J. Roy. Meteorol. Soc., 136, 997-1019, doi:10.1002/qj.614, 2010.

Luo, Y., Weng, Q. E. S., Wu, X. W., Gao, C., Zhou, X. H., and Zhang, L.: Parameter identifiability, constraint, and equifinality in data assimilation with ecosystem models, Ecol. Appl., 19(3), 571-574, 2009.

McFiggans, G., Artaxo, P., Baltensperger, U., Coe, H., Facchini, M. C., Feingold, G., Fuzzi, S., Gysel, M., Laaksonen, A., Lohmann, U., Mentel, T. F., Murphy, D. M., O’Dowd, C. D., Snider, J. R., and Weingartner, E.: The effect of physical and chemical aerosol properties on warm cloud droplet activation, Atmos. Chem. Phys., 6, 2593-2649, doi:10.5194/acp-6-2593-2006, 2006.

Nenes, A., Ghan, S., Abdul-Razzak, H., Chuang, P. Y., and Seinfeld, J. H.: Kinetic limitations on cloud droplet formation and impact on cloud albedo, Tellus, 53, 133-149, 2001.

Nenes, A., Charlson, R. J., Facchini, M. C., Kulmala, M., Laaksonen, A., and Seinfeld J. H.: Can chemical effects on cloud droplet number rival the first indirect effect?, Geophys. Res. Lett., 29(17), 1848, doi:10.1029/2002GL015295, 2002.

Neusüß, C., Wex, H., Birmili, W., Wiedensohler, A., Koziar, C., Busch, B., Brüggemann, E. Gnauk, T., Ebert, M., and Covert, D. S.: Characterisation and parameterization of atmospheric particle number-, mass-, and chemical-size during LACE 98 and MINT, J. Geophys. Res., 107(D21), 8127, doi:10.1029/2001JD000514, 2002.

Noone, K. J., Johnson, D. W., Taylor, J. P., Ferek, R. J., Garrett, T. J., Hobbs, P. V., Durkee, P. A., Nielsen, K., Platnick, S., King, M., Öström, E., O’Dowd, C. D., Smith, M., Russell, L. M., Flagan, R. C., Seinfeld, J. H., DeBock, L., VanGrieken, R. E., Hudson, J. G., Brooks, I., Gasparovic, R. F., and Pockalny, R. A.: A case study of ship track formation in a polluted marine boundary layer, J. Atmos. Sci., 57(16), 2748-2764, 2000.

O’Dowd, C. D., Facchini, M. C., Cavalli, F., Ceburnis, D., Mircea, M., Decesari, S., Fuzzi, S., Yoon, Y. J., and Putaud, J. P.: Biogenically-driven organic contribution to marine aerosol, Nature, 676-680, doi:10.1038/nature02959, 2004.

Partridge, D. G., Vrugt, J. A., Tunved, P., Ekman, A. M. L., Struthers, H., and Sorooshian, A.: Inverse modeling of cloudaerosol interactions - Part 2: Sensitivity tests on liquid phase clouds using a Markov Chain Monte Carlo based simulation approach, Atmos. Chem. Phys. Discuss., 11, 20051-20105, doi:10.5194/acpd-11-20051-2011, 2011.

Pérez, C. J., Martín, J., and Rufo, M. F.: Sensitivity estimations for Bayesian inference models solved by MCMC methods, Reliability Engineering and System Safety, 91, 1310-1314, 2006.

Platnick, S. and S. Twomey: Determining the susceptibility of cloud albedo to changes in droplet concentration with the Advanced Very High-Resolution Radiometer, J. Appl. Meteorol., 33, 334347, 1994.

Pollacco, J. A. P. and Angulo-Jaramilo, R.: A Linking Test that investigates the feasibility of inverse modeling: application to a simple rainfall interception model for Mt Gambier, southeast South Australia, Hydrol. Process., 23(14), 2023-2032, 2009.

Pruppacher, H. R. and Klett, J. D.: Microphysics of Clouds and Pre- cipitation (Atmospheric and Oceanographic Sciences Library), 976 pp., Springer, 1997.

Quinn, P. K., Bates, T. S., Coffman, D. J., and Covert, D. S.: Influence of particle size and chemistry on the cloud nucleating properties of aerosols, Atmos. Chem. Phys., 8, 1029-1042, doi:10.5194/acp-8-1029-2008, 2008.

Reutter, P., Su, H., Trentmann, J., Simmel, M., Rose, D., Gunthe, S. S., Wernli, H., Andreae, M. O., and Pöschl, U.: Aerosoland updraft-limited regimes of cloud droplet formation: influence of particle number, size and hygroscopicity on the activation of cloud condensation nuclei (CCN), Atmos. Chem. Phys., 9, 7067-7080, doi:10.5194/acp-9-7067-2009, 2009.

Rissman, T., Nenes, A., and Seinfeld, J. H.: Chemical amplification (or dampening) of the Twomey effect: Conditions derived from droplet activation theory, J. Atmos. Sci., 61(8), 919-930, 2004.

Roelofs, G. J.: On the drop and aerosol size dependence of aqueous sulfate formation in a continental cumulus cloud, Atmos. Environ., 26A, 2309-2321, 1992.

Roelofs, G. J. and Jongen, S.: A model study of the influence of aerosol size and chemical properties on precipitation formation in warm clouds, J. Geophys. Res., 109, D22201, doi:10.1029/2004JD004779, 2004.

San Martini, F. M., Dunlea, E. J., Grutter, M., Onasch, T. B., Jayne, J. T., Canagaratna, M. R., Worsnop, D. R., Kolb, C. E., Shorter, J. H., Herndon, S. C., Zahniser, M. S., Ortega, J. M., McRae, G. J., Molina, L. T., and Molina, M. J.: Implementation of a Markov Chain Monte Carlo method to inorganic aerosol modeling of observations from the MCMA-2003 campaign - Part I: Model description and application to the La Merced site, Atmos. Chem. Phys., 6, 4867-4888, doi:10.5194/acp-6-4867-2006, 2006.

Sorooshian, S. and Arfi, F.: Response-Surface Parameter Sensitivity Analysis-Methods for Post-Calibration Studies, Water Resour. Res., 18(5), 1531-1538, 1982.

Šimůnek, J., Wendroth, O., and van Genuchten M. T.: Parameter estimation analysis of the evaporation method for determining soil hydraulic properties, Soil Sci. Soc. Am. J., 62(4), 894-905, 1998.

Sorooshian, S. and Gupta V. K.: The Analysis of Structural Identifiability - Theory and Application to Conceptual Rainfall-Runoff Models, Water Resour. Res., 21(4), 487-495, 1985.

Sorooshian, S., Gupta, V. K., and Fulton J. L.: Evaluation of Maximum-Likelihood Parameter-Estimation Techniques for Conceptual Rainfall-Runoff Models - Influence of Calibration Data Variability and Length on Model Credibility, Water Resour. Res., 19(1), 251-259, 1983.

Sorooshian, A., Feingold, G., Lebsock, M. D., Jiang, H., and Stephens, G.: On the precipitation susceptibility of clouds to aerosol perturbations, Geophys. Res. Lett., 36, L13803, doi:10.1029/2009GL038993, 2009.

Takeda, T. and Kuba N.: Numerical Study of the Effect of CCN on the Size Distribution of Cloud Droplets .1. Cloud Droplets in the Stage of Condensation Growth, J. Meteorol. Soc. Jpn., 60(4), 978-993, 1982.

Tomassini, L., Reichert, P., Knutti, R., Stocker, T. F., and Borsuk M. E.: Robust Bayesian uncertainty analysis of climate system properties using Markov chain Monte Carlo methods, J. Climate, 20(7), 1239-1254, 2007.

Toorman, A. F., Wierenga, P. J., and Hills R. G.: ParameterEstimation of Hydraulic-Properties from One-Step Outflow 
Data, Water Resour. Res., 28(11), 3021-3028, 1992.

Tunved, P., Nilsson, E. D., Hansson, H. C., Strom, J., Kulmala, M., Aalto, P., and Viisanen, Y.: Aerosol characteristics of air masses in northern Europe: Influences of location, transport, sinks, and sources, J. Geophys. Res.-Atmos., 110(D7), D07201, doi:10.1029/2004JD005085, 2005.

Twomey, S.: Comparison of Constrained Linear Inversion and an Iterative Nonlinear Algorithm Applied to Indirect Estimation of Particle-Size Distributions, J. Comput. Phys., 18(2), 188-200, 1975.

Voutilainen, A. and Kaipio, J. P.: Sequential Monte Carlo estimation of aerosol size distributions, Comput. Stat Data An., 48(4), 887-908, 2005.

Voutilainen, A., Stratmann, F., and Kaipio, J. P.: A nonhomogeneous regularization method for the estimation of narrow aerosol size distributions, J. Aerosol Sci., 31(12), 1433-1445, 2000.

Vrugt, J. A., Bouten, W., and Weerts, A. H.: Information content of data for identifying soil hydraulic parameters from outflow experiments, Soil Sci. Soc. Am. J., 65(1), 19-27, 2001.

Vrugt, J. A., Gupta, H. V., Bastidas, L. A., Bouten, W., and Sorooshian, S.: Effective and efficient algorithm for multiobjective optimization of hydrologic models, Water Resour. Res., 39(8), 1214, doi:10.1029/2002WR001746, 2003.

Vrugt, J. A., Schoups, G., Hopmans, J. W., Young, C., Wallender, W. W., Harter, T., and Bouten W.: Inverse modeling of large-scale spatially distributed vadose zone properties using global optimization, Water Resour. Res., 40(6), W06503, doi:10.1029/2003WR002706, 2004.

Vrugt, J. A., Diks, C. G. H., Gupta, H. V., Bouten, W., and Verstraten J. M.: Improved treatment of uncertainty in hydrologic modeling: Combining the strengths of global optimization and data assimilation, Water Resour. Res., 41(1), W01017, doi:10.1029/2004WR003059, 2005.
Vrugt, J. A., Nualláin, B. Ó. B., Robinson, A., Bouten, W., Dekker, S. C., and Sloot, P. M. A.: Application of parallel computing to stochastic parameter estimation in environmental models, Comput. Geosci., 32(8), 1139-1155, 2006.

Vrugt, J. A., Stauffer, P. H., Wohling, T., Robinson, B. A., and Vesselinov V. V.: Inverse modeling of subsurface flow and transport properties: A review with new developments, Vadose Zone J., 7(2), 843-864, 2008.

Vrugt, J. A., Braak, C. J. F. Ter., Diks, C. G. H., Robinson, B. A., Hyman, J. M., and Higdon, D.: Accelerating Markov chain Monte Carlo simulation by differential evolution with selfadaptive randomized subspace sampling, International Journal of Nonlinear Sciences and Numerical Simulation., 10, 273-290, 2009a.

Vrugt, J. A., Robinson, B. A., and Hyman, J. M.: Self-adaptive multimethod search for global optimization in real-parameter spaces, IEEE Transactions on Evolutionary Computation, 13(2), 243 259, doi:10.1109/TEVC.2008.924428, 2009b.

Wraith, D., Alston, C., Mengersen, K., and Hussein, T.: Bayesian mixture model estimation of aerosol particle size distributions, Environmetrics, 22, 23-34, doi:10.1002/env.1020, 2009.

Yapo, P. O., Gupta, H. V., and Sorooshian, S.: Automatic calibration of conceptual rainfall-runoff models: Sensitivity to calibration data, J. Hydrol., 181(1-4), 23-48, 1996.

Zhang, Y., Seigneur, C., Seinfeld, J. H., Jacobson, M. Z., and Binkowski, F. S.: Simulation of aerosol dynamics: A comparative review of algorithms used in air quality models, Aerosol Sci. Technol., 31, 487-514, 1999.

Zhou, J., Swietlicki, E., Berg, O., Aalto, P., Hämeri, K., Nilsson, E., and Leek, C: Hygroscopic properties of aerosol particles over the central Arctic Ocean during summer, J. Geophys. Res., 106(D23), 32111-32123, 2001. 